\title{
ECOCIDIO: LA ODISEA DE UN CONCEPTO CON ASPIRACIONES JURÍDICAS ${ }^{1}$
}

\section{ECOCIDE: THE ODYSSEY OF A CONCEPT WITH LEGAL ASPIRATIONS}

\author{
PABlo SerRa PaLAO \\ Becario de la Escuela Diplomática de España \\ pabloserrapalao@gmail.com
}

Fecha de recepción: 1 de octubre de 2019 / Fecha de aceptación: 5 de noviembre de 2019

RESUMEN: Emprender un viaje al pasado permite dar respuesta a muchas de las incógnitas que gravitan sobre un determinado tema. Asimismo, también se puede decir que recorrer, desde una perspectiva analítica, la línea temporal que va dibujando a lo largo de la historia una cuestión concreta, ofrece una visión integral del asunto. Por consiguiente, para que los acontecimientos futuros tomen el rumbo deseado y finalmente se alcance la cristalización del crimen de ecocidio en el derecho internacional, resulta imprescindible conocer el origen y aquellos casos paradigmáticos que colocaron en primera fila el apremio por componer toda una base teórica que sustentara este crimen, además de la odisea conceptual que ha transitado el ecocidio hasta la fecha.

RESUM: Emprendre un viatge al passat permet donar resposta a moltes de les incògnites que graviten sobre un determinat tema. Així mateix, també es pot dir que recórrer, des d'una perspectiva analítica, la línea temporal que va dibuixant al llarg de la història una qüestió concreta, ofereix una visió integral de l'assumpte. Per tant, perquè tots els esdeveniments futurs prenguin el rumb desitjat i finalment s'assoleixi la cristal-lització del crim de l'ecocidi en el dret

\footnotetext{
${ }^{1}$ Las ideas reflejadas en la presente obra tienen su origen en el Trabajo Final del Máster Interuniversitario en Diplomacia y Relaciones Internacionales, curso 2018-2019.
} 
internacional, resulta imprescindible conèixer l'origen i aquells casos paradigmàtics que col-locaren en primera fila el constrenyiment per compondre tota una base teòrica que sustentés aquest crim, a més de l'odissea conceptual que ha transitat l'ecocidi fins avui.

ABSTRACT: Undertaking a journey into the past addresses many of the unknowns that gravitate around a certain subject. At the same time, it can also be said that, from an analytical perspective, travelling through the timeline that is drawn over history by a specific question offers a holistic vision of the issue. Therefore, in order that future events take the desired course and finally achieve the crystallisation of ecocide in international law, it is essential to understand the background and those paradigmatic cases that placed in the first row the urgency to build a whole theoretical framework to sustain this crime, and the conceptual odyssey that ecocide has experienced to date.

PALABRAS CLAVE: Ecocidio - Delito ambiental - Derecho internacional ambiental - Crimen internacional - Justicia climática.

PARAULES CLAU: Ecocidi - Delicte ambiental - Dret internacional ambiental Crim internacional - Justícia climàtica.

KEYWORDS: Ecocide - Environmental crime - International environmental law - International crime - Climate justice.

SUMARIO: I. Introducción. II. El ecocidio: de la práctica a su nacimiento como concepto. 1. Vietnam, los orígenes del ecocidio como concepto. 2. La ciencia, abanderada de la insurgencia. 3. La Primera Guerra del Golfo. III. El arduo camino de buscar una definición consensuada. 1. La Novena Enmienda a la Constitución de los Estados Unidos y el "derecho a la ausencia de ecocidio". 2. Falk y su guerra ambiental. 3. Los años 90' y el resurgir del ecocidio. 4. Polly Higgins: la activista que quiso poner fin al ecocidio en la Tierra. 5. El pragmatismo de Laurent Neyret como respuesta a la tesis maximalista de Higgins. IV. Conclusión. V. Bibliografía.

\section{INTRODUCCIÓN}

La voluntad de ver nacer nuevos conceptos que sean capaces de canalizar aspectos de la realidad hasta ese momento carentes de una definición apropiada, siempre ha sido un desafío sumamente atractivo para el mundo académico, al dar pie a la existencia de debates que permitan la contraposición 
de opiniones dispares sobre esa temática en concreto. Con todo, si lo que verdaderamente se pretende es que esa construcción conceptual se convierta en herramienta de cambio e incida positivamente en la sociedad, ha de trascender el ámbito estrictamente purista y aterrizar en el político y jurídico. La ilusión puesta en todo el trabajo de investigación que hay detrás de estas páginas se ha nutrido gracias a la propia convicción de que el ecocidio puede llegar a ser un auténtico instrumento transformador que otorgue respuestas a las exigencias actuales a la hora de proteger el medio ambiente.

Para que la regulación del crimen de ecocidio pueda perseguir tan nobles aspiraciones, se torna urgente y necesario el hacer frente a la controversia que suscita acotar su significado. Con tal propósito, y sin olvidar que el empeño del autor consiste en transmitir para todo público, de tal manera que su contenido pueda ser de utilidad, esta obra transitará por los inicios del ecocidio y aquellos acontecimientos posteriores que marcaron la exigencia de ver desarrollado este concepto en el plano teórico. De igual modo, y siendo fiel a una línea cronológica, se expondrán de manera pormenorizada las distintas acepciones que han ido apareciendo desde que se tiene conocimiento de la existencia del mismo como idea autónoma, identificando las discrepancias en su conceptualización.

Por lo tanto, las páginas subsiguientes albergan la humilde intención de brindar una visión global y ordenada de la procedencia de la temática a cualquier persona que no se encuentre familiarizada con la misma, de tal forma que le permita interiorizar y por lo tanto anticipar la suma trascendencia del tema que tiene entre manos. Por último, vale la pena dejar bien claro el deseo de esta obra por convertirse en un llamamiento sincero a todas aquellas personas especialistas en Derecho Ambiental para que, dejándose llevar por un activismo académico congruente con los tiempos que corren, tomen en consideración una herramienta, el crimen de ecocidio, para otorgar a las peores violaciones de la naturaleza la seriedad que se merecen, mejorando así la lucha contra la impunidad ambiental.

\section{EL ECOCIDIO: DE LA PRÁCTICA A SU NACIMIENTO COMO CONCEPTO}


La destrucción medioambiental ha estado ligada históricamente a la guerra, y pretender un estudio exhaustivo de los distintos enfrentamientos históricos en los que también se causaron estragos al entorno se aleja de la finalidad de esta obra. No obstante, resulta inexcusable efectuar al menos una breve mención al Stockholm International Peace Research Institute (SIPRI) y su labor pionera de indagación al respecto. Creado en 1966 con la misión de llevar a cabo investigaciones sobre seguridad, conflictos y paz, además de proporcionar análisis de políticas públicas y recomendaciones, en la época post-Vietnam se entregó al estudio del impacto de la guerra en el medio ambiente, labor gracias a la cual brotaron una serie de textos que pusieron el foco de atención en este problema de tan creciente relevancia: Ecological Consequences of the Second Indochina War (1976) ${ }^{2}$, Weapons of Mass Destructions and the Environment $(1977)^{3}$ y Warfare in a Fragile World: Military Impact on the Human Environment $(1980)^{4}$. En este último libro, Arthur H. Westing realiza una impecable tarea al examinar cada uno de los principales ecosistemas y su vulnerabilidad a la explotación de los mismos por parte de las fuerzas militares. De la misma manera, recopila toda una serie de batallas históricas en las cuales se perpetró algún tipo de daño medioambiental, ya sea colateral o intencionado. De las enumeradas en la obra, cabe destacar la contienda que se produjo entre persas y escitas en el año 512 a. C., en la que, al tiempo que se retiraban los escitas, desplegaron una estrategia de arrasar las tierras a su paso con la intención de evitar el avance persa ${ }^{5}$. Otro ejemplo llamativo en el cual alguno de los contendientes recurrió a esta política de "tierra quemada" fue en 1812 durante la incursión francesa en territorio ruso, evento enmarcado en las Guerras Napoleónicas (1796-1815). La maniobra rusa para frenar la invasión del ejército francés incluyó la destrucción íntegra del terreno por el que pasaba a medida

\footnotetext{
${ }^{2}$ Arthur H. Westing, Ecological Consequences of the Second Indochina War, SIPRI Publications, Taylor \& Francis, Londres, 1976.

${ }^{3}$ Arthur H. Westing, Weapons of Mass Destruction and the Environment, SIPRI Publications, Taylor \& Francis Londres, 1977.

${ }^{4}$ Arthur H. Westing, Warfare in a Fragile World: Military Impact on the Human Environment, SIPRI Publications, Taylor \& Francis, Londres, 1980 $<$ https://www.sipri.org/sites/default/files/files/books/SIPRI80Westing.pdf> [Última consulta, 3 de agosto de 2019].

5 lbíd., p. 14.
} 
que iba replegándose, de tal manera que los franceses no pudieran abastecerse de los recursos de la tierra ${ }^{6}$.

\section{Vietnam, los orígenes del ecocidio como concepto}

La evidencia expuesta en el párrafo anterior de que la causación de daños medioambientales graves ha integrado el modus operandi de cualquier beligerante en el transcurso de una guerra permite entrever, a grandes rasgos, que una de las peculiaridades de la propia esencia del ecocidio radica en que se sufrieron sus efectos antes de ser siquiera conceptualizado. Con respecto al surgimiento de su conceptualización propiamente dicha, tan solo hace falta recapitular algunas décadas atrás para poder encontrar el momento a partir del cual aparecerá con fuerza el empleo de este término, siendo las prácticas militares implementadas por Estados Unidos durante la Guerra de Vietnam el punto de partida. En este periodo, es sabido que el mundo en su totalidad fue testigo de las atrocidades que trajo consigo el mencionado conflicto, entre las cuales llamó la atención, ya sea por las estremecedoras imágenes o por las graves consecuencias que acarreó, la destrucción del medio ambiente con fines bélicos. Cuantificando las secuelas del conflicto en el plano ecológico, Christopher H. Lytton viene a detallar lo siguiente: During the conflict, the United States covered 10 percent of the surface area of Vietnam with various chemicals. The most notorious of these was Agent Orange, which destroyed nearly half of South Vietnam's mangrove forests. ${ }^{7}$

Tiene especial relevancia traer a colación el hecho de que, recién entrada la década de los años 70', ya habían emergido algunos textos que ofrecían un análisis desde la legalidad respecto al uso de tácticas militares con un efecto extremadamente pernicioso para el medio ambiente. Así, a modo de ejemplo, y sin pretensión alguna de ocupar mayor espacio expositivo, en 1971 el entonces miembro del Council on Foreign Relations (CFR) L. Craig Johnstone ya alertaba

\footnotetext{
${ }^{6}$ Ibíd., p. 15.

${ }^{7}$ Christopher H. Lytton, "Environmental Human Rights: Emerging Trends in International Law and Ecocide", Environmental Claims Journal, Vol. 13, № 1, 2000, p. 80. Traducción al castellano: "Durante el conflicto, los Estados Unidos cubrieron el 10 por ciento de la superficie de Vietnam con diversos químicos. El más destacado de ellos fue el Agente Naranja, el cual destruyó casi la mitad de los manglares de Vietnam del Sur." (Fuente: elaboración propia).
} 
sobre el peligro de que el uso de herbicidas como arma escalase hasta unos niveles en los cuales difícilmente pudiera ser parado o incluso revertido, sosteniendo que, en pleno crecimiento de una conciencia ambiental dentro de los Estados Unidos, llevar a cabo una política que permitiese una destrucción medioambiental sistemática constituía una actitud inconsistente y contraproducente ${ }^{8}$.

De igual modo, este diplomático estadounidense (quien además fue designado posteriormente Alto Comisionado Adjunto de las Naciones Unidas para los Refugiados $^{9}$ ), ya defendía, por aquel entonces, y aprovechando el debate en el Senado en torno a la ratificación del Protocolo sobre la prohibición del empleo en la guerra de gases asfixiantes, tóxicos o similares y de medios bacteriológicos de 1925 (comúnmente conocido como Protocolo de Ginebra) ${ }^{10}$, que Estados Unidos debía adoptar una posición firme a la hora de prohibir el uso de agentes químicos, gases lacrimógenos y herbicidas como métodos de guerra. Adicionalmente, y con arreglo a diversas investigaciones que tuvieron lugar en terreno, llegó a las siguientes conclusiones:

In the course of investigations of the program in Saigon and in the provinces of Vietnam, I found that the program was having much more profound effects on civilian noncombatants than on the enemy. (...) The program had its greatest effects on the enemy-controlled civilian populations of central and northern South Vietnam. In Vietnam the crop destruction program created widespread misery and many refugees. ${ }^{11}$

Con una mayoritaria opinión pública favorable a la adopción de medidas dirigidas a enmendar los nefastos errores de aquella intervención estadounidense,

\footnotetext{
${ }^{8}$ L. Craig Johnstone, "Ecocide and the Geneva Protocol", Foreign Affairs, Vol. 49, no 4, 1971, p. 718.

9 Asumió sus funciones como Alto Comisionado Adjunto de las Naciones Unidas para los Refugiados el 7 de junio de 2007 <https://www.unhcr.org/news/latest/2007/6/466807162/unhcrwelcomes-new-deputy-high-commissioner-I-craig-johnstone.html> [Última consulta, 6 de agosto de 2019].

10 Estados Unidos finalmente ratificó el Protocolo de Ginebra el 10 de abril de 1975 <http://disarmament.un.org/treaties/t/1925> [Última consulta, 6 de agosto de 2019].

11 Johnstone, "Ecocide and the Geneva..." cit., p. 719. Traducción al castellano: "En el curso de las investigaciones del programa en Saigón y en la provincias de Vietnam, descubrí que estaba teniendo unos efectos mucho más significativos en los civiles no combatientes que en el propio enemigo. [...] El programa tuvo sus mayores efectos en la población civil controlada por el enemigo de la zona central y septentrional de Vietnam del Sur. En Vietnam, el programa de destrucción de cultivo provocó una miseria generalizada y numerosos refugiados." (Fuente: elaboración propia).
} 
Johnstone sostenía que el Protocolo de Ginebra era una buena oportunidad para incluir la prohibición del gas lacrimógeno y el uso de herbicidas, en aras de vedar la guerra química y biológica. Finalmente, y teniendo en cuenta el contexto oportuno para ello, esto es, el debate en el Senado sobre la ratificación del Protocolo, Johnstone llega a la conclusión de que Estados Unidos tenía la obligación de esforzarse por obtener una interpretación unánime del Protocolo de Ginebra con la finalidad de prohibir el uso en la guerra de todos los gases, armas bacteriológicas y herbicidas ${ }^{12}$.

Siendo fiel a una línea cronológica que permita una mayor comprensión del auge que estaba tomando en aquella época la cuestión medioambiental, inmediatamente después de las aportaciones de L. Craig Johnstone, en 1973 el profesor estadounidense Richard A. Falk reflexionaba de forma completamente innovadora sobre la llamada environmental warfare, defendiendo su prohibición como una forma de anticipar daños futuros irreversibles. De esta manera, formuló toda una teoría crítica en torno a la "guerra ambiental" que caracterizó lo acontecido en Vietnam. Así, Falk incluía dentro de este concepto no solamente todas aquellas armas y tácticas militares cuyo objetivo concreto era destruir el medio ambiente, sino también aquellas que perturbasen las relaciones normales entre el ser humano y la naturaleza. El autor también reflexiona que procede tener en consideración la importancia de tratar el concepto de guerra ambiental desde una orientación basada en la ecología, ya que los lazos entre el ser humano y la naturaleza proporcionan un enfoque vital para la investigación ${ }^{13}$.

El análisis de Falk con respecto a la guerra ambiental practicada por Estados Unidos también brinda la evaluación de una serie de métodos bélicos específicos que, según él, perfectamente podían percibirse bajo la óptica de la guerra ambiental, tales como el uso de herbicidas, topadoras modificadas (las llamadas Rome Plows) utilizadas para la deforestación del terreno, el bombardeo y la artillería pesada, además de, tal y como se ha podido comprobar, el despliegue de técnicas de manipulación del clima ${ }^{14}$. La estructura empleada en la exposición

\footnotetext{
12 Ibíd., p. 720.

${ }^{13}$ Richard A. Falk, "Environmental Warfare and Ecocide - Facts, Appraisal and Proposals", Revue Belge de Droit International, Vol. $1, \quad 1973$, p. $\quad$ 8-9 <http://rbdi.bruylant.be/public/index.php?module_id=00000000009\&rec_id=00000021562_0000 0011782> [Última consulta, 10 de septiembre de 2019].

14 lbíd., p. 9.
} 
de cada uno de estos métodos parte desde una explicación general, pasando por presentar las razones militares y legales que supuestamente se invocaban para justificar estas prácticas, hasta arribar a la propia valoración jurídica que él realiza de cada una de ellas.

A modo de ejemplo, y de manera que se pueda comprender mejor la perspectiva de Falk en relación con el resto de métodos bélicos enumerados, resulta especialmente útil dar a conocer en esta obra las observaciones de este profesor estadounidense en cuanto al uso de herbicidas. Con brillante capacidad analítica, tras mencionar el químico más conocido, el Agente Naranja, no se olvida de insistir en que fueron utilizados otros químicos nocivos para el medio ambiente y la salud, tales como el Agente Blanco (rociado contra bosques y selvas) o el Azul (diseminado principalmente para acabar con todo tipo de cultivos). Las consecuencias del uso de estos químicos no solamente se redujeron a cuantificar la superficie fumigada (más de dos millones de hectáreas aproximadamente), sino también a la cantidad de población que se vio afectada directamente (la cifra supera con creces el millón de personas), sin olvidar tampoco que las evidencias existentes sacaban a la luz la vinculación directa que había entre las malformaciones en los fetos y la exposición a estos químicos. Desde el posicionamiento militar, parece que privar al Frente Nacional de Liberación de Vietnam de comida y protección natural pesaba más en la balanza. Sustentando lo anterior, el Gobierno de los Estados Unidos se escudaba al afirmar que no existía normativa internacional que prohibiese el uso de herbicidas con fines bélicos. A pesar de las instituciones que proferían estas fundamentaciones, Falk en ningún momento se sintió intimidado, puesto que refleja en el papel una valoración jurídica tan sólida que, a juicio del autor de esta obra, desmonta por completo aquel reprobable intento de justificar actos totalmente desproporcionados ${ }^{15}$.

Mención aparte requiere el hecho de que, gracias a las aportaciones de Falk, se elevó la calidad del debate post-Vietnam en lo que respecta a la importancia de fortalecer mediante puntos de vista argumentados la consolidación de la demanda social existente, de la cual emanaba una exigencia de rendición de cuentas a todos los actores involucrados, así como la búsqueda de suficientes

${ }^{15}$ lbíd., p. 9-18. 
garantías orientadas a impedir la reiteración en el futuro de los errores cometidos.

\section{La ciencia, abanderada de la insurgencia}

Toda persona que se haya entregado a la lectura de esta obra quizá tenga la sensación, llegada a este punto, de que, si bien es cierto que el detonante histórico a partir del cual surge con ímpetu el concepto de ecocidio ha quedado completamente revelado, no sucede lo mismo a propósito del instante exacto en el que emerge el mismo. Con voluntad de esclarecer tal inquietud, Rosel Soler Fernández recuerda que fue el profesor Arthur W. Galston, biólogo de la Universidad de Yale, quien utilizó por vez primera este término en $1970^{16}$. La historia de Arthur W. Galston cumple rigurosamente con el prototipo de aquel científico cuya bienintencionada aportación al mundo de la ciencia es aprovechada posteriormente para fines, cuanto menos, perversos. Se ha considerado necesario revelar a continuación por qué es tan importante este precursor de la bioética para el posterior protagonismo que tuvo el ecocidio en el debate social y político.

Tal y como el propio Galston relata, durante las investigaciones que finalmente culminaron en su tesis doctoral en 1943, pudo averiguar que un determinado compuesto químico (en concreto, el ácido 2,3,5-triyodobenzoico, o TIBA, por sus siglas en inglés) podía aumentar la floración y en consecuencia el número de vainas de soja listas para cosechar. Del mismo modo, y en el curso de estas investigaciones, Galston halló que, en concentraciones elevadas, este compuesto químico era capaz de causar efectos altamente perjudiciales para la planta, como por ejemplo su deshoje prematuro. Muy a su pesar, años después fue consciente de que el Cuerpo Químico del Ejército de los Estados Unidos había utilizado este compuesto químico como modelo para formular otros defoliantes mucho más efectivos, entre los cuales destacó el llamado Agente Naranja ${ }^{17}$. El uso que se le había dado a su descubrimiento fue lo que le motivó

\footnotetext{
${ }^{16}$ Rosel Soler Fernández, "El ecocidio: ¿crimen internacional?", bie3: Boletín I.E.E.E, no 8, 2017, p. 859-873 <http://www.ieee.es/Galerias/fichero/BoletinesIEEE3/2017/boletinieee8.pdf> [Última consulta, 10 de agosto de 2019].

${ }^{17}$ Arthur W. Galston, "Science and Social Responsibility: A Case History", Annals of the New York Academy of Sciences, Vol. 196, Issue 4, 1972, p. 223-235.
} 
a impulsar un movimiento subversivo dentro del ámbito científico, lanzando un llamamiento abierto para abolir el uso de químicos en la guerra. Suficientes personalidades de su entorno se sumaron a la evocación que hacía Galston sobre la primacía que había de tener la ética en los fines dados a todos aquellos descubrimientos científicos, llegando incluso a dirigir una carta al Presidente de los Estados Unidos Lyndon B. Johnson reprobando el uso de herbicidas en Vietnam ${ }^{18}$. Pocos años antes de fallecer, Galston recordaba aquellas épocas de la siguiente manera:

Two other 'decision points' affected my life greatly. (...) The second critical decision developed out of our government's use of Agent Orange and other chemicals to defoliate and kill vegetation during the war in Vietnam. This violated my deepest feelings about the constructive role of science, and moved me into active opposition to official U.S. policy. (...) Our small group was eventually successful in helping to change our country's policy, when President Nixon ordered the end of the spraying at the end of 1970, almost five years before the end of the war. ${ }^{19}$

Lo compartido en las páginas anteriores deja bien claro que a principios de la década de los años 70' el debate acerca de la posibilidad de juzgar por crímenes ambientales era una realidad latente. Era tal la sensación que, incluso, y como bien recoge Saloni Malhotra, durante el discurso inaugural de la Conferencia de las Naciones Unidas sobre el Medio Humano (también conocida como Cumbre de la Tierra), celebrada en Estocolmo los días 5 a 16 de junio de 1972, el entonces primer ministro sueco Olof Palme se refirió a la Guerra de Vietnam como un ecocidio ${ }^{20}$. Olof Palme no se encontró aislado ante aquella audiencia a

\footnotetext{
18 lbíd., p. 233-234.

${ }^{19}$ Arthur W. Galston, "An Accidental Plant Biologist", Plant Physiology, Vol. 128, Issue 3, 2002, p. 787 <http://www.plantphysiol.org/content/plantphysiol/128/3/786.full.pdf> [Última consulta, 11 de agosto de 2019]. Traducción al castellano: "Otras dos «decisiones vitales» tuvieron una gran influencia en mi vida. (...) La segunda decisión crucial surgió a raíz de la utilización del Agente Naranja y otros químicos por parte de nuestro gobierno para defoliar y eliminar la vegetación durante la Guerra de Vietnam. Esta actuación quebrantó mis sentimientos más profundos sobre la labor constructiva de la ciencia, lo cual me llevó a una oposición activa frente a la política oficial de los Estados Unidos. (...) Eventualmente, nuestro pequeño grupo tuvo éxito a la hora de ayudar a cambiar la política de nuestro país, cuando el Presidente Nixon ordenó el fin de las fumigaciones a finales de 1970, casi cinco años antes del final de la guerra." (Fuente: elaboración propia).

${ }^{20}$ Saloni Malhotra, "The International Crime That Could Have Been But Never Was: An English School Perspective on the Ecocide Law", Amsterdam Law Forum, Vol. 9, no 3, 2017, p. 52-53 <http://amsterdamlawforum.org/article/view/408/553> [Última consulta, 11 de agosto de 2019].
} 
la hora de subrayar la catástrofe medioambiental que había significado la invasión de Vietnam, llamando la atención con esta alusión a quienes habían sido los principales responsables. De acuerdo con un informe elaborado para el Human Rights Consortium de la Universidad de Londres, la primera ministra de India, Indira Gandhi, y el jefe de la delegación de China, Tang Ke, también señalaron las consecuencias medioambientales, y no solo humanas, de la guerra $^{21}$. No obstante, muy probablemente de forma intencionada, el término ecocidio finalmente no llegó a quedar plasmado en ningún documento una vez finalizada la Cumbre.

\section{La Primera Guerra del Golfo}

Se ha sopesado el valor que tenía para ultimar la historia que envuelve el surgimiento del ecocidio reflexionar sobre los daños medioambientales que tuvieron lugar durante la Primera Guerra del Golfo (1990-1991). Aun siendo conscientes del salto temporal que ocasiona esto, es indiscutible que los acontecimientos acaecidos en este conflicto concedieron todavía más razones de peso para que la comunidad internacional en su conjunto le prestara mayor atención a la necesidad de crear una herramienta eficaz con la suficiente capacidad para juzgar este tipo de actos, dándole fuerza legitimadora al hecho de buscar un consenso sobre el ecocidio y ofrecer una respuesta a tales crímenes ambientales. Es por ello que el cierre de esta parte consistirá en una modesta introducción de las más sonoras atrocidades medioambientales cometidas en la invasión iraquí a Kuwait, lo cual sirvió para fortalecer la narrativa de barajar el ecocidio como una solución a la persecución de responsables de daños graves al medio ambiente e incorporar este criterio enjuiciador en el terreno de la normativa internacional.

Numerosa bibliografía se ha encargado de la Primera Guerra del Golfo22, por lo que el cometido de estas líneas simplemente se reduce a poner de relieve los

\footnotetext{
${ }^{21}$ Anja Gauger, Mai Pouye Rabatel-Fernel, Louise Kulbicki, Damien Short y Polly Higgins, The Ecocide Project: "Ecocide is the missing 5th Crime Against Peace", Human Rights Consortium, Londres, 2013, p. 5 <https://sas-space.sas.ac.uk/4830/> [Última consulta, 12 de agosto de 2019]. 22 Un análisis exhaustivo sobre la crisis del Golfo Pérsico se puede encontrar en José B. Acosta Estévez, Aspectos jurídicos de la crisis del Golfo Pérsico, Tesis Doctoral dirigida por Joan Lluís Piñol i Rull, Universitat de Girona, Departament de Dret Públic, 1993 <http://hdl.handle.net/10803/7685> [Última consulta, 12 de agosto de 2019].
} 
motivos que hicieron de esta crisis otro instante remarcable en este relato cronológico. Una vez realizada esta advertencia y sin más dilaciones, todo el interés ha de enfocarse en aquellos sucesos vinculados a la invasión iraquí que provocaron un menoscabo grave al medio ambiente.

Aaron Schwabach, en un completo análisis que realiza sobre la legalidad de las acciones perpetradas por el gobierno de Sadam Husein contra los árabes de las marismas y la zona de humedales (región declarada Patrimonio Mixto de la Humanidad por la Unesco en $2016^{23}$ ) en la que habitaban, comienza resaltando los actos contra el medio ambiente ejecutados por orden de Sadam Husein y materializados en el marco de los ataques lanzados a Kuwait. Schwabach pone el énfasis en el incendio provocado por el ejército iraquí de 600 pozos de petróleo pertenecientes a Kuwait así como el deterioro de otros 175, vertiéndose deliberadamente al menos seis millones de barriles de petróleo a las aguas del Golfo Pérsico ${ }^{24}$. Teniendo en cuenta que cada barril de crudo contiene aproximadamente 159 litros, las cifras son desgarradoras. De igual manera, Christopher H. Lytton determina que estos eventos encajan claramente en el ámbito de la definición de ecocidio, rescatando de las aportaciones de este autor que aquellos pozos de petróleo a los que no les había alcanzado el fuego inundaron igualmente el desierto con crudo a causa de los estragos desatados ${ }^{25}$. Concluyendo con el impacto en cifras, José B. Acosta Estévez rescata el contenido de un Comunicado con fecha 1 de mayo de 1991 publicado por la Organización Meteorológica Mundial, en el cual se indica que en los incendios de las instalaciones petrolíferas de Kuwait se consumieron cinco millones de barriles de petróleo y 70 millones de metros cúbicos de gas por día ${ }^{26}$.

Por otro lado, sería una imprudencia pasar por alto que, de las numerosas resoluciones del Consejo de Seguridad de las Naciones Unidas que tuvieron en el punto de mira la invasión de Kuwait por el Irak de Sadam Husein, un número

\footnotetext{
23 Toda la información relativa a la denominación por la Unesco de este sitio como Patrimonio Mixto de la Humanidad puede encontrarse en <http://whc.unesco.org/en/list/1481/> [Última consulta, 13 de agosto de 2019].

${ }^{24}$ Aaron Schwabach, "Ecocide and Genocide in Iraq: International Law, the Marsh Arabs, and Environmental Damage in Non-International Conflicts", Colorado Journal of International Environmental Law \& Policy, Vol. 15, no 1, 2004, p. 1 <https://ssrn.com/abstract=442541> [última consulta, 5 de septiembre de 2019].

${ }^{25}$ Lytton, "Environmental Human Rights..." cit., p. 82-83.

${ }^{26}$ Acosta Estévez, Aspectos jurídicos... cit., p. 214-215.
} 
para nada desdeñable de ellas contemplaron la responsabilidad de Irak por los daños, lesiones o perjuicios sufridos por Kuwait y por terceros Estados, sus nacionales o empresas, como resultado de la invasión y la ocupación ilegal de Kuwait por el ejército iraquí27. Pero más importante resulta para las pretensiones de este escrito apuntar que la Resolución 687 (1991), de 3 de abril de 1991, recoge expresamente que dentro de esa responsabilidad de Irak por toda pérdida y daño directo como consecuencia de sus actos, se incluían aquellos daños provocados al medio ambiente y la destrucción de recursos naturales.

Evidentemente, hubiera sido deseable dedicarle a este caso una profundización más acorde a su trascendencia histórica. Frente a este deseo, hay que recordar las limitaciones de la presente obra, entendiendo la utilidad de evocar los atentados a la naturaleza que se sucedieron en el contexto de la Primera Guerra del Golfo como la de ir asimilando aquellos episodios claves en el apogeo del ecocidio dentro del ideario internacional ambiental.

La sucesión de acontecimientos históricos que se han ido revisando, por encontrarse íntimamente conectados con la aparición del ecocidio en el panorama político y jurídico, permiten, o al menos esa era la intención, continuar la lectura habiendo adquirido al menos una base adecuada como para no perder de vista los orígenes de este término. Teniendo claras todas las singularidades de su procedencia práctica será mucho más provechoso transitar seguidamente a lo largo y ancho de su evolución en el plano teórico, intrincado cometido que se tratará de afrontar de la mejor manera posible en el próximo apartado.

\section{EL ARDUO CAMINO DE BUSCAR UNA DEFINICIÓN CONSENSUADA}

Tal y como vaticina el enunciado del presente apartado, los elementos de la realidad que se han congregado bajo el concepto de ecocidio no han sido siempre los mismos. Es más, no resulta descabellado defender que la búsqueda de una delimitación del término ha sido muy divergente dependiendo de su procedencia, bien se haya tratado desde una tendencia minimalista o bien a partir de aquellas posiciones con una inclinación hacia una definición más

\footnotetext{
${ }^{27}$ De entre todas las Resoluciones del Consejo de Seguridad dictadas en el contexto del conflicto Irak-Kuwait, pueden destacarse las siguientes: Resolución 674 (1990), de 29 de octubre de 1990; Resolución 686 (1991), de 2 de marzo de 1991 y Resolución 687 (1991), de 3 de abril de 1991.
} 
amplia. La estructura que se ha considerado más adecuada a fin de exponer las diversas definiciones ha sido la cronológica, lo cual favorecerá una interiorización mayor de la evolución que ha ido experimentando la noción del ecocidio.

\section{La Novena Enmienda a la Constitución de los Estados Unidos y el "derecho a la ausencia de ecocidio"}

Aun no habiendo calado tan hondo como se hubiera esperado, llama la atención, no solamente por su temprana aparición (1971) sino más aun por la sugerente propuesta, la formulación de un "derecho constitucional a la ausencia de ecocidio" de la mano de Harry W. Pettigrew. Este profesor de la Universidad de Ohio respaldaba su teoría interpretando el ecocidio como the substantial destruction of an integral part of a particular ecosystem or the unreasonable degradation of the environment in general. ${ }^{28} \mathrm{Al}$ plantear un derecho inherente a la persona, Pettigrew parte desde una postura antropocéntrica del problema, como la mayoría de aportaciones teórico-jurídicas elaboradas de este periodo.

La mirada puesta en el ser humano en lugar de en los propios valores intrínsecos a la naturaleza puede percibirse como una distorsión inconsciente de la problemática, lo cual tampoco ha de quitar mérito a las observaciones de Pettigrew, las cuales proponen un encuadre totalmente innovador para la fecha. En este sentido, considera el derecho a la ausencia de ecocidio como un derecho individual fundamental, quedando bajo el paraguas protector de la Novena Enmienda a la Constitución de los Estados Unidos. Del texto de la Novena Enmienda, contenida en la Carta de Derechos de los Estados Unidos, se desprende que la enumeración expresa de determinados derechos en la Constitución no ha de ser interpretada para negar o desacreditar otros derechos retenidos por el pueblo ${ }^{29}$. De esta manera, Pettigrew concibe que la Novena

\footnotetext{
${ }^{28}$ Harry W. Pettigrew, "A Constitutional Right of Freedom from Ecocide", Environmental Law, Vol. 2, no 1, 1971, p. 1. Traducción al castellano: "la destrucción significativa de una parte vital de un ecosistema en particular o la degradación desproporcionada del medio ambiente en general." (Fuente: elaboración propia).

29 "Amendment IX: The enumeration in the Constitution, of certain rights, shall not be construed to deny or disparage others retained by the people", The Bill of Rights: A Transcription, National Archives <https://www.archives.gov/founding-docs/bill-of-rights-transcript> [Última consulta, 16 de agosto de 2019].
} 
Enmienda permite garantizar el derecho a la ausencia de ecocidio, al incluirlo en esa categoría imprecisa de derechos "retenidos" por el pueblo ${ }^{30}$.

\section{Falk y su guerra ambiental}

En páginas anteriores, cuando se iban descubriendo los eventos históricos que mayor influencia tuvieron en la revelación del ecocidio como idea pionera en la conciencia ambiental que se estaba gestando, se bautizaba a Richard A. Falk como uno de sus precursores. Ya se dejó claro que Falk, valiéndose del profundo rechazo que originó la guerra ambiental desplegada en la península de Indochina, sustentó que era prioritario dar pasos firmes hacia la prohibición de armas y tácticas de guerra que infligieran daños medioambientales graves, señalando en consecuencia el inmenso valor que tenía la atribución de una nueva categoría de crimen a los efectos de la guerra que destruyeran irreversiblemente un ecosistema concreto ${ }^{31}$. La agudeza de Falk allanó el camino para que sus propuestas quedasen ilustradas en un proyecto de Convención Internacional sobre el Crimen de Ecocidio, cuyo artículo 2 preceptúa lo siguiente:

Article II

In the present Convention, ecocide means any of the following acts committed with intent to disrupt or destroy, in whole or in part, a human ecosystem:

a) The use of weapons of mass destruction, whether nuclear, bacteriological, chemical, or other;

b) The use of chemical herbicides to defoliate and deforest natural forests for military purposes;

c) The use of bombs and artillery in such quantity, density, or size as to impair the quality of soil or the enhance the prospect of diseases dangerous to human beings, animals, or crops;

d) The use of bulldozing equipment to destroy large tracts of forest or cropland for military purposes;

\footnotetext{
30 Pettigrew, "A Constitutional Right..." cit., p. 18.
}

${ }^{31}$ Falk, "Environmental Warfare..." cit., p. 18. 
e) The use of techniques designed to increase or decrease rainfall or otherwise modify weather as a weapon of war;

f) The forcible removal of human beings or animals from their habitual places of habitation to expedite the pursuit of military or industrial objectives. $^{32}$

El innegable alcance que obtuvo la creación desde cero de todo un proyecto de Convención Internacional no impide alertar ciertos interrogantes. Cuidando de no caer en la trampa de practicar un revisionismo histórico, lo cual únicamente provocaría sabotear la importancia que tiene el proyecto de Falk en la progresiva viabilidad de finalmente ver regulado el ecocidio, hubiera sido deseable mayor precisión conceptual en varios aspectos. La primera falta de precisión se aprecia cuando se procede a una lectura conjunta de los artículos 1 y 2: mientras que del primero de ellos se infiere que el ecocidio en tiempos de paz también sería considerado como un crimen internacional ${ }^{33}$, en el artículo siguiente, al pormenorizar los distintos actos que serían catalogados como tal (los cuales se acaban de transcribir), "la mayor parte" de los mismos solo pueden ser entendidos en un escenario bélico. Y se hace hincapié en que son "la mayoría" puesto que la segunda falta de precisión conceptual que se ha de destacar se hallaría en el artículo 2 apartado f), en el cual se contempla la acción de ocasionar un desplazamiento forzado de seres humanos o animales de sus lugares habituales de asentamiento para acelerar la consecución de objetivos

32 Ibíd., p. 21. Traducción al castellano: "Artículo II. En la presente Convención, se entiende por ecocidio cualquiera de los siguientes actos cometidos con la intención de alterar o destruir, en todo o en parte, un ecosistema humano:

a) El uso de armas de destrucción masiva, ya sean nucleares, bacteriológicas, químicas, u otras:

b) El uso de herbicidas químicos para defoliar y deforestar superficies forestales con fines militares;

c) El uso de bombas y artillería en tal cantidad, densidad o tamaño que menoscabe la calidad del suelo o aumente la propagación de enfermedades peligrosas para los seres humanos, los animales o los cultivos;

d) El uso de equipos de demolición para destruir grandes superficies forestales o tierras cultivables con fines militares;

e) El uso de técnicas destinadas a aumentar o disminuir las precipitaciones o a modificar de cualquier otro modo las condiciones meteorológicas como arma de guerra;

f) El desplazamiento forzado de seres humanos o animales de sus lugares habituales de asentamiento para acelerar la consecución de objetivos militares o industriales." (Fuente: elaboración propia).

${ }^{33}$ Artículo I del Proyecto de Convención Internacional sobre el Crimen de Ecocidio: "Las Partes Contratantes confirman que el ecocidio, tanto si se comete en tiempos de paz como en tiempos de guerra, es un crimen de Derecho Internacional que se comprometen a prevenir y sancionar." (Traducción al castellano: elaboración propia). 
militares "o industriales" (recordar que siempre ha de existir la intención de alterar o destruir, en todo o en parte, un ecosistema humano). Que el desplazamiento sea motivado por agilizar la obtención de objetivos de uno "u otro" tipo (del inglés: to expedite the pursuit of military or industrial objectives), abre la veda a una ingente cantidad de casos que, acogiéndose a esta ausencia de precisión delimitadora, podrían deducirse como contenidos dentro de los parámetros del ecocidio de Falk.

Más allá de haber puesto el énfasis en las puntualizaciones llevadas a cabo, se está completamente de acuerdo con las palabras que Sandrine Maljean-Dubois le dedica a la obra de Falk, al advertir que influyó enormemente en generar la necesidad de integrar en el Derecho Internacional Humanitario ${ }^{34}$ (o ius in bello, aquel campo del Derecho Internacional que regula las conductas de los combatientes en un conflicto armado, con el fin de aliviar y prevenir el sufrimiento humano) la exigencia de proteger el medio ambiente ${ }^{35}$.

En conclusión, de lo visto anteriormente se entiende que el planteamiento alrededor del concepto de ecocidio sostenido por Falk es aplicable en situaciones de conflictos armados. Esta posición es comprensible si se tiene en cuenta que la época apremiaba una denuncia clara al desastre ecológico de Vietnam así como un exhorto al Gobierno de los Estados Unidos para que, en la medida de lo posible, destinase de inmediato recursos para la reparación de esos daños.

\footnotetext{
${ }^{34}$ Existe una cantidad ingente de bibliografía centrada en el Derecho Internacional Humanitario. Para ahondar en el tema, y con la única intención de ejemplificar, se destacan las siguientes obras consultadas por el autor durante el proceso de investigación: Etienne Kuster (coord.) y Nils Melzer, Derecho Internacional Humanitario: Una Introducción Integral, Comité Internacional de la Cruz Roja, Ginebra, $2016<$ https://www.icrc.org/es/publication/derecho-internacionalhumanitario-una-introduccion-integral> [Última consulta, 18 de agosto de 2019]; Julia Grignon, "The beginning of application of international humanitarian law: A discussion of a few challenges", International Review of the Red Cross, Vol. 96, no 893, 2014, p. 139-162 $<$ https://www.icrc.org/en/international-review/article/beginning-application-internationalhumanitarian-law-discussion-few> [Última consulta, 19 de agosto de 2019]; Marko Milanovic, "The end of application of international humanitarian law", International Review of the Red Cross, Vol. 96, no 893, 2014, p. 163-188 <https://www.icrc.org/en/international-review/article/endapplication-international-humanitarian-law> [Última consulta, 19 de agosto de 2019]; y Cesáreo Gutiérrez Espada y María José Cervell Hortal, El Derecho Internacional en la encrucijada. Curso General de Derecho Internacional Público, Editorial Trotta, Madrid, 2012 (3ª edición), p. 418-432. ${ }^{35}$ Sandrine Maljean-Dubois, "À propos de «Environmental Warfare and Ecocide. Facts, Appraisal and Proposals" de Richard Falk (1973-I): l'écocide et le droit international, de la guerre du Vietnam à la mise en péril des frontières planétaires", Revue Belge de Droit International, Vol. $48, n^{\circ} 1-2,2015$, p. 361.
} 


\section{Los años 90 ' y el resurgir del ecocidio}

La primera década de los años 90' se abría, tal y como ha sido comentado, con la declaración de guerra por parte del ejército iraquí al invadir Kuwait. A la tragedia ecológica sufrida durante la Primera Guerra del Golfo, ilustrada en la desgarradora imagen de los pozos petrolíferos kuwaitíes envueltos en llamas, le sucedió el también aludido ecocidio de Sadam Husein en la zona de las marismas del sur de Irak. El ya citado profesor de la Thomas Jefferson School of Law, Aaron Schwabach, relata que, tras un frustrado alzamiento de los árabes de las marismas contra el gobierno de Sadam en 1991, la respuesta implacable del ejecutivo consistió en un ataque prolongado a lo largo de los años que, unido a las cientos de miles de personas que se vieron empujadas a dejar atrás sus hogares, vació casi por completo los humedales mediante un complejo entramado de construcciones orientadas a tal $\mathrm{fin}^{36}$. Las agresiones al medio ambiente consumadas sin meditar siquiera en las irreparables secuelas que traerían consigo, avivaron los peores recuerdos de la Guerra de Vietnam, recibiendo por consiguiente un rechazo unánime por parte de la comunidad internacional. En las palabras de David Zierler se puede apreciar perfectamente lo que significaron los actos de Sadam Husein: It is notable that in Saddam Hussein, we see that the major perpetrator of environmental warfare since the Vietnam War was also, arguably, the greatest violator of the norms of warfare in general in recent times. ${ }^{37}$

Es apreciable que el ecocidio continuó, en base a estos acontecimientos, encasillado en aquellos actos cometidos durante la guerra.

Sin desdeñar lo manifestado con anterioridad, de lo escrito por Stephen McCaffrey en 1990 se divisa nítidamente que la concepción que se tenía del ecocidio comenzaba a actualizarse conforme iba madurando la conciencia ecologista. Pese a que esté permitido declarar con certeza que McCaffrey no llega a componer una verdadera teoría en torno al ecocidio, puesto que se limita a echar mano del término sin clarificar qué había de entenderse como tal, de su

\footnotetext{
${ }^{36}$ Schwabach, "Ecocide and Genocide..." cit., p. 3-4.

37 Zierler, The Invention of Ecocide... cit., p. 167. Traducción al castellano: "Cabe destacar que, no solamente vemos en Sadam Husein al mayor causante de una guerra ambiental desde la Guerra de Vietnam, sino también, probablemente, al mayor infractor de las normas generales de la guerra en los últimos tiempos." (Fuente: elaboración propia).
} 
lectura se deduce que lo utiliza con la siguiente pretensión: apuntar a ciertos daños medioambientales provocados por la contaminación del ser humano cuyos efectos en un ecosistema determinado fuesen prácticamente irreversibles ${ }^{38}$. Tomando como caso de estudio la regulación de las aguas de ríos internacionales, aboga por una "ecogestión" de los mismos, debiendo ser tratado su cauce como un sistema único y descartando rotundamente cualquier tipo de intento de fraccionar el río en atención a la soberanía de los Estados por los cuales discurre ${ }^{39}$. Por lo que atañe a las soluciones que pone sobre la mesa, todas parten desde una perspectiva institucionalista, en el sentido de crear comisiones conjuntas para la gestión de ríos que sean patrocinadas por organizaciones internacionales preexistentes o en el seno de nuevos organismos concebidos para tal $\mathrm{fin}^{40}$.

Poco ofrece McCaffrey a la necesidad de ver legitimada una teoría sobre el ecocidio con una consistencia suficiente como para no adolecer de fisuras conceptuales. Mas resaltar a este autor en el recorrido marcado por la presente obra tiene su razón de ser en demostrar, una vez más, que el cambio de mentalidad emergente y la consecuente preocupación por la relación entre el ser humano y los múltiples elementos de la biosfera ${ }^{41}$ estaba siendo secundado desde numerosas iniciativas.

Partiendo de esa lógica de sentido común de McCaffrey haciendo un uso del término que lo relaciona con ese alarmante incremento de la contaminación, en 1994 ya se advierte que el cariz del asunto comienza a adoptar un rumbo sin precedentes. Ludwik A. Teclaff traza un cambio de orientación al apostar por una mirada completamente vanguardista: considera que, si el ecocidio era entendido mayoritariamente como una destrucción masiva del medio ambiente, entonces no existía barrera que impidiese aplicarlo en tiempos de paz, al ocurrir en incontables ocasiones más allá de un escenario bélico ${ }^{42}$. Siendo este autor uno de los primeros (si no el primero) en abogar firmemente por esta postura (se

\footnotetext{
38 Stephen McCaffrey, "The Law of International Watercourses: Ecocide or Ecomanagement?", Revista Jurídica Universidad de Puerto Rico, Vol. 59, № 4, 1990, p. 1003-1012.

39 lbíd., p. 1008.

40 lbíd., p. 1010-1012.

41 lbíd., p. 1012.

42 Ludwik A. Teclaff, "Beyond Restoration - The Case of Ecocide", Natural Resources Journal, Vol. 34, no 4, 1994, p. 933-934 <https://digitalrepository.unm.edu/nrj/vol34/iss4/6> [Última consulta, 6 de septiembre de 2019].
} 
podrá recordar que, si bien Richard Falk alude en su proyecto de convención al ecocidio en tiempos de paz, no había nada más desglosado en este sentido), realiza un efectivo repaso de toda una serie de catástrofes ambientales que bien podían ser calificadas como ecocidio ${ }^{43}$. Asimismo, dejando en evidencia lo laxa que era la normativa internacional existente en cuanto a la reclamación de responsabilidad y correspondiente sanción por daños medioambientales, argumenta la necesidad de incidir en la responsabilidad de los Estados. De su discurso se puede entrever que va encauzando la cuestión impulsado por su intensa crítica dirigida hacia la tibia respuesta que había ido formulando la comunidad internacional para atajar las diferentes situaciones de ecocidio, afirmando que los Estados habían venido esforzándose por minimizar sus responsabilidades ${ }^{44}$.

De ahí que Teclaff defienda que bautizar como crimen internacional las consecuencias ecológicas que pudieran derivarse de ciertas actividades podría llevar aparejado un poderoso efecto disuasorio ${ }^{45}$, propiciando que sea revertida la costumbre de no tomar en consideración el efecto negativo sobre el medio ambiente al ejercer determinadas prácticas. Pero en la anterior propuesta se esconde una encrucijada: dibujar la línea divisoria entre el crimen internacional y la responsabilidad civil por un hecho dañoso. Recalcando la obligación que tienen los Estados de no deteriorar el medio ambiente, para Teclaff la clave entre encontrarse ante una u otra opción radicaría en la magnitud de la destrucción medioambiental acaecida, presenciando un crimen internacional cuando el deterioro supera los niveles comprendidos dentro del hecho dañoso ${ }^{46}$. Encima, asegura que si se admite el ecocidio con su oportuna responsabilidad penal

\footnotetext{
43 Ibíd., p. 937-939. El autor repara en casos tan renombrados como son el accidente en la costa de la Bretaña francesa del buque Amoco Cadiz en 1978, causando un vertido de 230.000 toneladas de crudo y convirtiéndose en uno de los mayores de la historia; o del petrolero Exxon Valdez en Prince William Sound (Golfo de Alaska) en 1989, incidente que provocó un derrame de aproximadamente 34.000 toneladas de petróleo, acentuándose el desastre medioambiental debido a las cualidades ecológicas de la zona. Un detallado estudio de estos casos puede hallarse en César Rodríguez Quintana, La contaminación marina causada por el transporte de hidrocarburos en buques tanque: accidentes, legislación preventiva e indemnizaciones a las víctimas de mareas negras, Tesis Doctoral dirigida por Enrique Melón Rodríguez y Santiago Iglesias Baniela, Universidad de La Laguna, Departamento de Ingeniería Agraria, Náutica, Civil y Marítima, Área de Ciencias y Técnicas de la Navegación, 2008 <https://www.educacion.gob.es/teseo/imprimirFicheroTesis.do?idFichero=tpcO1DDDPE0\%3D> [Última consulta, 6 de septiembre de 2019].

44 Ibíd., p. 954-955.

45 Ibíd., p. 952.

46 Ibíd., p. 953.
} 
internacional, ello podría reforzar y hasta actualizar el papel del Consejo de Seguridad de las Naciones Unidas, con la finalidad de verificar posibles casos de ecocidio y desplegar con todo rigor la potestad de dictar decisiones vinculantes acompañadas de sanciones ${ }^{47}$. Por supuesto, si cualquier persona se queda embelesada con la teoría, esto resulta altamente llamativo. No obstante, es notorio que la efectividad del Consejo de Seguridad a la hora de mantener la paz y seguridad ha brillado por su ausencia en más ocasiones de las que se imaginan, siendo manipulado este órgano por la capacidad de veto de sus cinco miembros permanentes (China, Francia, Rusia, Reino Unido y Estados Unidos).

Simultáneamente, Teclaff también es consciente de la controversia que suscita este enfoque. Por ende, estima como viable, en aras de frenar la oposición de no pocos Estados en ver crecer este concepto, y sobre todo si se desea una colaboración activa de los mismos, que el ecocidio pueda ser tenido en cuenta en el ámbito de la responsabilidad civil, más bien como un perjuicio agravado (evitando, por lo tanto, las connotaciones que conlleva identificarlo como un crimen internacional) $)^{48}$.

En suma, es evidente que Teclaff se empeña en la responsabilidad de los Estados, centrando este tema toda su atención. Sin embargo, esquiva una materia de indispensable discusión, y es la responsabilidad de los individuos en este tipo de actuaciones. Aparte, siquiera barajar la posibilidad de que el ecocidio se reduzca a un agravante en el ámbito de la responsabilidad civil, y a pesar del atractivo que tiene esta oferta por su gran capacidad de mitigar las discrepancias que genera ver consagrado el ecocidio como crimen, es una ocurrencia un tanto imprudente, corriendo el peligro de abrir la puerta a constreñir indefinidamente la ambición de esta herramienta. Una ambición que, si no se deja perder la oportunidad, puede llegar a transformarse en un instrumento poderoso en la búsqueda de una responsabilidad penal ambiental a nivel internacional.

Llega el turno de fijar toda la atención en un estudio que marcó sobradamente la bibliografía subsiguiente: The International Crime of Ecocide (1996) ${ }^{49}$. En él, Mark Allan Gray expone, con una capacidad de síntesis envidiable, un depurado

\footnotetext{
47 lbíd., p. 955.

48 lbíd., p. 953.

49 Mark Allan Gray, "The International Crime of Ecocide", California Western International Law Journal, Vol. 26, no 2, 1996, p. 215-272.
} 
análisis por medio del cual desglosa cada uno de los puntos que pudiesen llevar aparejada algún tipo de controversia terminológica: desde las características del daño, pasando por el tipo de responsabilidad y los actores culpables del mismo, hasta los derechos violados o la legitimación para incoar el respectivo proceso. Con carácter previo a entrar en detalle, Gray anuncia la definición de ecocidio con la que trabajará a lo largo de la obra, haciendo saber que está abierta a su perfeccionamiento: Ecocide is identified on the basis of the deliberate or negligent violation of key state and human rights and according to the following criteria: (1) serious, and extensive or lasting, ecological damage, (2) international consequences, and (3) waste. $^{50}$

Hasta la fecha nadie había desmontado el término y estudiado con tanta atención cada una de las piezas que, combinadas, conformaban tan valioso instrumento. Gray supo reconocer la carencia latente de un marco teórico que brindase una cierta coherencia a la narrativa que iba, por decirlo de alguna manera, improvisándose sobre el ecocidio. Por ello, se aventuró a precisar, uno por uno, los diversos parámetros que se encargaban de su demarcación teórica. A continuación, se rescatan aquellas valoraciones estimadas como imprescindibles para las aspiraciones de esta obra, al haberse convertido en una extraordinaria fuente de inspiración para la literatura del presente siglo focalizada en esta temática.

Lo que hace Gray con su propia definición es descomponerla ordenadamente. En primer lugar, se advierte que para poder hablar de ecocidio, en esa "vulneración deliberada o negligente de derechos humanos o estatales" ha de producirse un daño grave al medio ambiente, debiendo sus efectos abarcar una extensión amplia de territorio o, en su caso, que se prolonguen en el tiempo. Por lo que respecta a la exigencia de gravedad, y según lo especificado por este autor, puede emanar tanto de la magnitud del daño y el número de especies afectadas, como del impacto en términos económicos y sociales para el ser

\footnotetext{
50 Ibíd., p. 216. Traducción al castellano: "El ecocidio se identifica partiendo de la vulneración deliberada o negligente de derechos humanos o estatales y de conformidad con los siguientes criterios: (1) daño ecológico grave, ya sea extenso o prolongado en el tiempo, (2) consecuencias internacionales, y (3) desperdicio." (Fuente: elaboración propia).
} 
humano. Al referirse a la dilatación de los efectos, el autor remite a que existan pocas probabilidades de revertirlos en un plazo aceptable ${ }^{51}$.

El siguiente de los criterios es que las consecuencias de ese daño ecológico sean internacionales. Gray contempla que lo que está en juego son los mismos valores e intereses de la comunidad internacional, por lo que para remediar sus efectos es primordial abordarlo desde la cooperación internacional ${ }^{52}$.

El último de los criterios que ha de concurrir de acuerdo con este autor es el de "desperdicio" o "derroche". Esta novedosa incorporación, hasta ese momento inexplorada, la justifica al disponer que los hechos susceptibles de ser etiquetados como ecocidio son perpetrados a sabiendas de la pérdida ecológica que traen consigo, a la vez que hacen caso omiso a la oportunidad de respaldar alternativas mucho más eficientes y respetuosas con el medio ambiente. Al señalar que el ecocidio desperdicia los recursos naturales, imposibilita el crecimiento de esas alternativas y favorece la brecha de riqueza, Gray explicita el acierto de agregar el "derroche" como pauta que facilite distinguir aquellos casos de ecocidio ${ }^{53}$.

Las contribuciones de Mark Gray sobrepasan lo referido en los párrafos previos. Lo que se ha querido traer aquí solo ha sido lo relativo a la configuración de una definición de ecocidio, sirviendo como un valioso recurso en la persecución de un consenso doctrinal, algo que se ha tornado impostergable si de verdad se anhela que este crimen cristalice como una herramienta realmente efectiva.

Mark A. Drumbl cerró la década y, por lo tanto, también lo hará con este subapartado. Sin restarle relevancia a sus esfuerzos para desarraigar la noción de destrucción medioambiental del contexto bélico, al propugnar por la consolidación de crímenes ambientales más allá de la guerra, sin embargo no se puede omitir la precipitación del autor al desatender las diferencias

\footnotetext{
51 Ibíd., p. 217.

52 Ibíd.

${ }^{53}$ Ibíd., p. 217-218.
} 
sustanciales entre el ecocidio y geocidio ${ }^{54}$, empleándolos indistintamente ${ }^{55}$. El anterior desliz teórico podría justificarse en su ferviente crítica conducida hacia todas aquellas personalidades académicas que, según Drumbl, se habían ceñido a la discusión de todo tipo de apreciaciones definitorias, abstrayéndose en esos debates alejados de la realidad de lo verdaderamente importante: cómo llevar a la práctica el potencial enjuiciador de una figura como el ecocidio ${ }^{56}$.

Es innegable que cualquier persona puede caer cautivada con facilidad por el efecto tentador de tal afirmación, la cual carga contra ese purismo teórico obcecado en arribar a una definición perfecta, pero sucumbir a ello sería una enorme equivocación. Siendo aquí palpable el desacuerdo con Mark Drumbl, resulta obvio que una construcción teórica que tenga más bien pocas intenciones de buscar una aplicabilidad práctica, es lo que se ha de evitar en esta clase de invitaciones a la reflexión. Pero esa voluntad de mutar en un impulsor de transformación social de nada servirá si la base teórica no es lo suficientemente sólida como para aguantar la ofensiva de quien quiera abalanzarse en su contra. Por consiguiente, la labor de erigir una acepción que pueda lograr un consenso más que razonable se vuelve inevitable.

Con todo, las ideas proporcionadas por Drumbl en la implementación del ecocidio son dignas de un merecido espacio en esta obra. Conviene remarcar brevemente cómo sintetiza los aspectos que para él son clave de este crimen internacional. Dicho esto, el autor interpreta que el ecocidio se resume en un quebrantamiento del deber de cuidado, incumplimiento que ha podido materializarse a través de un acto deliberado, como por medio de negligencia ${ }^{57}$. En adición, ve innecesario que solamente pueda categorizarse como ecocidio aquellas circunstancias en las que el daño sea grave, extenso y prolongado en

\footnotetext{
${ }^{54}$ El concepto de "geocidio" no tiene cabida en esta obra ya que se considera ampliamente superado. La característica que lo distingue del ecocidio básicamente subyace en que el primero gira en torno a la violación del derecho humano a un ambiente sano, siendo una tesis puramente antropocentrista. En cambio, el núcleo del ecocidio se halla en el perjuicio ecológico per se. Si se desea profundizar en este asunto, es de obligada lectura Lynn Berat, "Defending the Right to a Healthy Environment: Toward a Crime of Geocide in International Law", Boston University International Law Journal, Vol. 11, oㅡ 2, 1993, p. 327-348.

55 Mark A. Drumbl, "Waging War Against the World: The Need to Move from War Crimes to Environmental Crimes", Fordham International Law Journal, Vol. 22, oㅜ 1, 1998, p. 142 $<$ https://ir.lawnet.fordham.edu/ilj/vol22/iss1/3/> [Última consulta, 9 de septiembre de 2019].

56 lbíd., p. 144.

57 Ibíd., p. 142-143.
} 
el tiempo, sopesando como alternativa simplemente la causación de daños. De esta manera, las autoridades que, en su caso, vayan a ser competentes del enjuiciamiento, pueden tener mayor discreción a la hora de calificar los hechos, ensanchando así el alcance de la responsabilidad y aumentando a su vez la efectividad de esta figura jurídica ${ }^{58}$.

Empero, esta proposición tan sugerente no constituye una excusa suficiente como para darse el lujo de acabar de un plumazo con la trascendencia que ha de tener la graduación de los efectos del daño, más aun si se está teorizando acerca de un crimen internacional en el que múltiples elementos están en juego. Igualmente, es conveniente que la condena que pueda acarrear un acto de este tipo sea estipulada con arreglo a la gravedad del mismo y de conformidad con una escala bien definida que refleje aquellos niveles de punibilidad. Dejar rienda suelta a la discrecionalidad del órgano enjuiciador supone un riesgo añadido y alimenta la discordancia al condenar sucesos similares. En conclusión, parece más apropiado admitir que el ecocidio ha de quedar circunscrito a las situaciones de mayor gravedad.

Como se ha podido observar, la década de los años 90' fue testigo de un enérgico desarrollo doctrinal, hasta el punto de alcanzar una madurez destacable: de la valentía de Teclaff al ubicar el ecocidio en tiempos de paz, pasando por la alentadora y tan completa teoría de Gray, hasta el planteamiento más práctico de Drumbl, el ecocidio fue adquiriendo una legitimidad cada vez mayor. Preparar el terreno para el cambio siempre ha requerido de un enriquecimiento en el plano de las ideas capaz de sensibilizar a la sociedad, obteniendo el apoyo fundamental para ver satisfechas reivindicaciones como esta. Que logre prosperar el ecocidio comportará una evolución significativa en la relación existente entre el ser humano, la naturaleza y el resto de especies, además de asumir la obligación de cuidado que le incumbe al ser humano. Los ríos de tinta correspondientes a la década analizada con toda seguridad habrán contribuido a ello.

\section{Polly Higgins: la activista que quiso poner fin al ecocidio en la Tierra}

\footnotetext{
58 Ibíd., p. 143-144.
} 
El descomunal trabajo de incidencia desplegado por la abogada ambientalista Polly Higgins en estos últimos años, ha sido de tal envergadura que solo admite comparación con el activismo político practicado por aquel científico que en su época alzó la voz frente a la destrucción medioambiental de la Guerra de Vietnam, Arthur W. Galston. La dedicación plena de Higgins a la consagración del ecocidio como crimen internacional se ha vuelto esencial para colocar contra las cuerdas a quienes les aterra y, por consiguiente, tratan de ralentizar, tan inminente victoria. "La abogada de la Tierra" supo canalizar, con un estilo impecable y aprovechando su experiencia como letrada, el desafío que entraña fomentar a instituciones y ciudadanía para que puedan visualizar la plasmación del ecocidio en un cuerpo normativo como un paso crucial en la imparable progresión dentro del campo de la protección al medio ambiente.

Claramente, y como era de esperar, Higgins será quien acapare todos los focos en esta parte. Por lo pronto, vale la pena efectuar siquiera una breve alusión a varias personas previas a Higgins que a comienzos del presente siglo se envalentonaron a tratar tan intrincado asunto.

Para empezar, y aunque Christopher Lytton se empeñara en situar el valor a proteger en el derecho humano a un medio ambiente sano, por lo que el encuadre en efecto es puramente antropocéntrico ${ }^{59}$, se apoyó en las aportaciones de Mark Gray sobre el ecocidio para ajustar sus propias conclusiones. Lytton acentúa la utilidad que puede tener un concepto jurídico de este calibre para afianzar su propio criterio, según el cual la comunidad internacional ha de lograr un equilibrio entre aquel sector que reclama la codificación de unos derechos de la naturaleza y aquellas opiniones partidarias de un antropocentrismo descontrolado ${ }^{60}$. Poco más se puede decir sobre este autor, ya que las opciones que pone sobre la mesa no son, ni mucho menos, novedosas (concebir una convención de derechos humanos ambientales o la cristalización del ecocidio como crimen internacional bajo competencia de la Corte Penal Internacional), y no gozan de la extensión adecuada ${ }^{61}$. Tampoco parece nada acertado haberse animado a declarar que dotar de derechos a la

\footnotetext{
${ }^{59}$ Lytton, "Environmental Human Rights..." cit., p. 73-82.

60 lbíd., p. 85.

61 lbíd., p. 85-87.
} 
naturaleza irremediablemente implica una relegación automática a un segundo plano del derecho que tiene el ser humano a mejorar su calidad de vida ${ }^{62}$. Esta fijación enmascara un antropocentrismo cuya peligrosidad consiste en desprender unos efectos ciertamente perjudiciales para la salvaguarda de los distintos ecosistemas. Escudarse en una noción como la "calidad de vida", cuya connotación por lo general se ve impregnada del marco ideológico en el cual se encuadra el discurso, puede ser aprovechado para avalar el crecimiento económico a toda costa, boicoteando aspiraciones ecologistas al tacharlas de "fanatismo ambiental"63.

Seguidamente, sobresale por sus propios méritos el pensamiento de Franz Broswimmer, quien irrumpía con fuerza a comienzos de siglo colocando en tela de juicio al sistema financiero preponderante, la globalización y al frenetismo de un crecimiento económico sin límites. El resultado de su indagación quedó grabado en un completo estudio que viaja a través de la evolución del ser humano, identificando los puntos de inflexión que provocaron alteraciones en la conexión entre la especie humana y la naturaleza, motivando pérdidas de biodiversidad así como una progresiva aparición de casos de ecocidio ${ }^{64}$. Desde un enfoque histórico-sociológico, Broswimmer ofrece una explicación íntegra de la extinción masiva de especies y su indiscutible vinculación con la conducta que iba adoptando el ser humano en cuanto a su relación con el entorno. Sentenciando que el ecocidio constituye la cara destructiva de la evolución cultural ${ }^{65}$, la aventura en la que se embarca Broswimmer no tiene precedente alguno ni es comparable con ningún otro trabajo, al haber examinado de cerca la destrucción provocada por la especie humana desde los inicios de su historia, estructurada por el impacto originado en los distintos tipos de sociedades que fueron sucediéndose.

El modus operandi en la investigación de Broswimmer se traduce en presentar el estudio de las causas del ecocidio y la extinción masiva de especies en cada una de las fases históricas: desde las sociedades premodernas, pasando por

\footnotetext{
62 lbíd., p. 87.

63 lbíd.

${ }^{64}$ Franz J. Broswimmer, Ecocide: A Short History of the Mass Extinction of Species, Pluto Press, Londres, 2002.

65 Ibíd., p. 28.
} 
una etapa temprana de la era moderna y el respectivo surgimiento del capitalismo, hasta desembocar en la época inmediatamente posterior a la Segunda Guerra Mundial. Un acercamiento interdisciplinar que atribuye valiosos recursos histórico-sociológicos para fortalecer los cimientos de una doctrina sobre el crimen de ecocidio.

Arremetiendo sin ningún tapujo mediante palabras cargadas de crítica al modelo económico y social, son imprescindibles las aportaciones de Broswimmer en cuanto al análisis de la globalización, sobre todo si se tiene en cuenta que su libro fue publicado en pleno apogeo de tal estructura hegemónica. Evidenciando la marca ecológica que tanto caracteriza a la globalización, Broswimmer apunta con pulso firme a quienes ostentan un papel protagonista en este vertiginoso sendero plagado de eventos delirantes, que no hacen más que hipotecar el futuro de la humanidad:

Global markets are now dominated by global mega-corporations which are among the most undemocratic and unaccountable of human institutions. (...) These corporations not only pursue profits in low-wage markets but also seek to escape the tighter regulatory frameworks of the global North, thus greatly accelerating the destruction of ecosystems and biodiversity in the global South. (...) Ever larger areas of the global landscape are drawn into the exclusive orbit of corporate globalization, accelerating 500 years of ecological degradation and progressive ecocide. In short, neo-liberal globalization constitutes the last and most destructive phase of global industrialization. 66

Finalmente, Broswimmer da en el clavo al volcarse decididamente por querer transmitir una mirada optimista de tal derrotero con predecible final trágico, al confiar en que una democracia que priorice los valores ecologistas es factible. El autor, acuñando el término "democracia ecológica", apela al cada vez mayor

\footnotetext{
66 Ibíd., p. 86-88. Traducción al castellano: "Los mercados globales están ahora dominados por megacorporaciones internacionales, las cuales se hallan entre las instituciones más antidemocráticas e irresponsables existentes. (...) Estas corporaciones no solo buscan ganancias en mercados de bajos salarios, sino también escapar de los marcos regulatorios más estrictos del hemisferio Norte, acelerando enormemente de este modo la destrucción de los ecosistemas y la biodiversidad en el hemisferio Sur. (...) Una superficie cada vez mayor del paisaje global se ve arrastrada a la órbita exclusiva de la globalización corporativa, acelerando 500 años de degradación ecológica y ecocidio continuado. En pocas palabras, la globalización neoliberal constituye la última y más destructiva fase de la industrialización global." (Fuente: elaboración propia).
} 
respaldo de movimientos verdes, por la paz y feministas, cuya visión conjunta y cualidad sensibilizadora puede dar una respuesta a las necesidades del planeta $^{67}$. En esta misma dirección, propone que el sistema democrático se empape de una mayor participación del individuo en la toma de decisiones que le afecten, lo cual estimula la promoción de una auténtica justicia social y ayuda a recuperar la dignidad de la persona, secuestrada por los intereses propios del modelo económico reinante ${ }^{68}$.

Como colofón final, Broswimmer pronuncia un mensaje esperanzador al apostar por que una sociedad en la cual prevalezca la justicia social y climática no sea solo una cosa condenada a quedar atrapada en el imaginario colectivo, sino que puede tornarse en una realidad perfectamente plausible en el futuro. Depositando la confianza en el propio ser humano, en la capacidad que tiene de revertir la situación y en su tesón por autosuperarse, divisa un mañana en el que semejante escenario de ecocidio continuado haya sido completamente superado, habiéndose rectificado el abanico de valores morales imperantes en la sociedad y, con ello, la percepción que se tiene de la relación existente entre la especie humana y la naturaleza. De ese vínculo, el ser humano tendrá que abrazar su condición de ser parte integrante y, por supuesto, dependiente.

Ahora sí, Higgins. Las expectativas creadas no son para nada infundadas, ya que la lucha incansable de este célebre personaje por ver nacer el proyecto al cual dedicó tantos años de su vida, la ha convertido en toda una referente en esta temática, siendo la principal fuente inspiradora tanto para juristas con experiencia en Derecho Internacional Ambiental como para movimientos climáticos en pleno apogeo. Lamentablemente, en abril de 2019, un cáncer implacable, de aquellos que no permiten entrever ni un ápice de optimismo, se la llevó69. Es por ello que el cometido de estas páginas no solamente se reduce a transmitir y elogiar su trabajo, sino que constituyen también un homenaje a su persona y legado. El autor de esta obra se dará ampliamente por satisfecho si llega a difundir mínimamente el testimonio que dejó Polly Higgins.

\footnotetext{
67 lbíd., p. 97-102.

68 lbíd., p. 100.

69 Jonathan Watts, "Polly Higgins, lawyer who fought for recognition of 'ecocide', dies aged 50", The Guardian, 22 de abril 2019 <https://www.theguardian.com/environment/2019/apr/22/pollyhiggins-environmentalist-eradicating-ecocide-dies> [Última consulta, 12 de septiembre de 2019].
} 
Sentado lo anterior, su activismo con ley en mano eclosionó poco antes del año 2010, instante en el cual zarandeaba el entumecido Derecho Internacional Ambiental gracias a la publicación de un libro que dejaría al descubierto el sustrato del pensamiento de Higgins, Eradicating Ecocide. Con la misma efusividad, en ese periodo propuso a la Comisión de Derecho Internacional de las Naciones Unidas un proyecto de ley internacional sobre el crimen de ecocidio. De más está decir que los años venideros estuvieron abarrotados de una actividad frenética encaminada en exclusiva a erigir este crimen.

Más adelante, en 2012 veía la luz Earth is our Business: changing the rules of the game. El descomunal trabajo de Higgins en este segundo libro consiste en suministrar una cantidad ingente de respuestas legales en las que poder ampararse siempre que sea preciso, ya sea para plantarle cara al más que probable sermón reaccionario procedente del mundo del Derecho, o para frenarle los pies a cualquier corriente cuya única motivación sea colocar obstáculos a lo largo de tan complicado periplo. De hecho, no solamente proporciona un proyecto de Ley de Ecocidio que estaría lista para poner en práctica en el Reino Unido ${ }^{70}$, sino que también el libro alberga un supuesto de acusación por ecocidio, resultado de un simulacro de juicio desarrollado el 30 de septiembre de 2011 ante el Tribunal Supremo de Inglaterra y Gales, cuyo veredicto ficticio, aplicando la citada ley, encontró culpables de una serie de delitos de ecocidio a los directores ejecutivos de dos empresas petrolíferas ${ }^{71}$. Amplias dosis de sentido común impregnan el discurso de Higgins, plenamente consciente de la emergencia que entraña la situación actual. Es por eso que otro de los anexos que facilita, el cual trae consigo una enorme aplicabilidad práctica, es una guía de principios que habrían de ser contemplados a la hora de juzgar cualquier caso de ecocidio ${ }^{72} \mathrm{e}$, incluso, engrandece el activismo legal gracias a la redacción de una revolucionaria evaluación ambiental para todos aquellos proyectos que presumiblemente vayan a ser financiados por el Banco Mundial,

\footnotetext{
70 Polly Higgins, Earth is our Business: changing the rules of the game, Shepheard-Walwyn (Publishers) Ltd., Londres, 2012, p. 157-170.

71 lbíd., p. 155-156.

72 lbíd., p. 171-178.
} 
lo cual aportaría mayores garantías de que los mismos sean ambientalmente respetuosos y sostenibles ${ }^{73}$.

Esta abogada británica tenía bien claro el calibre de uno de los aspectos más representativos de la ley, su dualidad. Por un lado, y actuando como motor, Higgins afirma que el sistema legal ha legitimado y alentado el abuso del planeta por los seres humanos, siendo las leyes las que han conferido el derecho a explotar y contaminar, desencadenando así un desequilibrio de tales dimensiones que amenaza con desestabilizar la Tierra y, fruto de ello, la propia existencia de la especie humana ${ }^{74}$. En contraposición, y atendiendo a la otra cara de la misma moneda, está profundamente convencida de que una vía sustancial para afrontar la crisis climática a la que se enfrenta la humanidad es, precisamente, la propia ley: Only by implementing international laws and mechanisms premised on intrinsic values will we embed the recognition of the inherent rights of nature and create the powerful shift in business and consciousness that is vital to turn our world around. ${ }^{75}$

En definitiva, Higgins ha sabido captar a la perfección la capacidad que tiene la ley para elevarse como mecanismo configurador de un nuevo marco de intervención que actúe eficazmente e interrumpa la vorágine en la que está sumida el ser humano, la cual arroja a la debacle a todos los seres que habitan la Tierra.

En lo concerniente a la comprensión del ecocidio de Polly Higgins, ofrece una perspectiva totalmente innovadora, con varios matices que dibujan su singularidad con respecto al resto de acepciones que habían estado apareciendo en décadas pasadas. Falta aclarar que Higgins lanzó al mundo este concepto en su primer libro, Eradicating Ecocide, por lo que sus escritos subsiguientes siempre estuvieron apoyados en esta apreciación del problema:

For the purpose of international law, I propose the following definition for ecocide:

\footnotetext{
73 Ibíd., p. 179-190.

74 lbíd., p. 148-149.

75 Ibíd., p. 149. Traducción al castellano: "Solo mediante la aplicación de leyes y mecanismos internacionales basados en valores intrínsecos seremos capaces de integrar el reconocimiento de los derechos inherentes a la naturaleza y crear una poderosa transición en el comercio y la conciencia, vital para dar un vuelco a nuestro mundo." (Fuente: elaboración propia).
} 
The extensive destruction, damage to or loss of ecosystem(s) of a given territory, whether by human agency or by other causes, to such an extent that peaceful enjoyment by the inhabitants of that territory has been severely diminished. ${ }^{76}$

Si esta descripción se coteja con otras de diversa autoría en las que se ha reparado previamente, se pueden apreciar nítidamente esos matices a los que se aludía hace un momento. Por ejemplo, es fácilmente detectable que el punto de vista de Higgins deriva de la corriente del Derecho de la Tierra ${ }^{77}$, ámbito en el que esta letrada fue una de las impulsoras con mayor credibilidad $^{78}$. De acuerdo con la autora, tal ángulo de observación supone distinguir entre un ecocidio ocasionado por actividades humanas y otro natural, provocado este último por eventos naturales (tales como tsunamis, terremotos o inundaciones, entre otros). En suma, entiende el ecocidio como cualquier colapso de un ecosistema determinado, independientemente de que el actuar del ser humano haya sido causante de tal catástrofe o no ${ }^{79}$.

\footnotetext{
76 Polly Higgins, Eradicating Ecocide: Laws and governance to prevent the destruction of our planet, Shepheard-Walwyn (Publishers) Ltd., Londres, 2015 (2 $2^{\text {a }}$ edición), p. 62-63. Traducción al castellano: "A los efectos del derecho internacional, propongo la siguiente definición de ecocidio: La destrucción masiva, el daño o la pérdida de un ecosistema o ecosistemas de un territorio determinado, ya sea debido a la acción humana o a otras causas, hasta tal punto que el disfrute pacífico por los habitantes de ese territorio se ha visto gravemente disminuido." (Fuente: elaboración propia).

77 Ibíd., p. 151-154. El prisma imperante en el ámbito del Derecho de la Tierra, o Derecho de la Madre Tierra, se puede decir que tiene bastantes puntos en común con la Teoría de los Derechos de los Animales (TDA). Higgins, en su libro Eradicating Ecocide, defiende el reconocimiento de derechos a la naturaleza entendiéndolo como un instrumento de protección idóneo para aquellas situaciones en las que el planeta sufre cualquier daño provocado por el ser humano y, como es lógico, carece de voz para señalar semejante injusticia. Por lo tanto, la autora considera que si se le otorgaran derechos propios, las personas podrían estar legalmente facultadas para proteger el entorno natural en el cual habitan exigiendo el respeto de tales derechos. Así, por ejemplo, Higgins sostiene que alegar la violación del "derecho a vivir libre de contaminación" de la naturaleza sería un buen remedio para paliar la dificultad actual de probar en la vía judicial un nexo causal entre el daño medioambiental y el impacto negativo en la salud de las personas, estableciéndose con estos derechos una conexión directa y evidente. Asimismo, esta autora añade que alegar el crimen de ecocidio supone un derecho implícito de la comunidad en su conjunto, esto es, los derechos de la naturaleza, los humanos y los animales no humanos, fortaleciendo el nexo causal entre el daño cometido y la violación de estos derechos. En definitiva, supone corregir la percepción mercantilista que se tiene de la naturaleza y anteponer el valor intrínseco de la misma.

78 Higgins, Earth is our business... cit., p. 6-7. Desde 2007 que Higgins abogó por la creación de este nuevo cuerpo normativo. Incluso, fue invitada para intervenir en la Conferencia de las Naciones Unidas sobre Cambio Climático de 2008, en donde aprovechó la oportunidad para incluir en su discurso la propuesta de una Declaración Universal de Derechos Planetarios.

79 lbíd., p. 3-4.
} 
La definición que proporciona Higgins podría quedar categorizada sin problema dentro de las tesis maximalistas, al haber construido un concepto de una amplitud que permite integrar prácticamente cualquier caso de deterioro ambiental que ostente una repercusión significativa. Ahora bien, cuesta interiorizar la operatividad que puede llegar a tener visualizar el ecocidio de este modo tan holgado, con la única discriminación entre aquellos eventos en los que existe una injerencia humana y los que no por medio de dos tipos de ecocidio: human-made ecocide y naturally occurring ecocide. La protagonista de este razonamiento, previendo la ostensible controversia que podría llegar a desatar introducir en el mismo saco la destrucción ambiental de cierta envergadura independientemente del actor que la origine, fue tan meticulosa que incluso preparó una sección de preguntas y respuestas ${ }^{80}$. Allí, sintetiza que la utilidad de incluir los hechos naturalmente acaecidos como un ecocidio estriba en que tal "ecocidio natural" llevaría aparejado la confección de un deber de cuidado, a raíz del cual se prevea proporcionar asistencia a todos aquellos (seres vivos, se presume) que se hayan visto perjudicados o inmersos en un riesgo provocado por el colapso masivo de un ecosistema, instaurándose una obligación legal de ayudar por parte de los Estados ${ }^{81}$.

No obstante, quizás existan mayores ventajas al dejar que este crimen comprenda tan solo aquellos acontecimientos en los que la agencia humana haya tenido algo que ver. Agrupar en la misma definición los eventos naturales, generando una dicotomía de un término que aún tardará por estar disponible para ser aplicado, puede llegar a jugar en contra de la necesidad de verlo nacer como crimen internacional con toda celeridad. Si lo que se pretende es que el deber de cuidado quede garantizado como resultado de acaecimientos catalogados como catástrofes naturales, puede ser más práctico echar mano de otros mecanismos legales para ello. No parece existir imperativo alguno de estirar el ámbito de un concepto que todavía no ha encontrado la aceptación deseada, poniendo en peligro su efectividad e implementación, además de diluir la consistencia del mismo.

80 lbíd., p. 191-196.

81 lbíd., p. 193. 
Aparte, obligado apunte merece la compleja cuestión de la intencionalidad en este tipo de actos. La completa doctrina elaborada por Higgins acierta con exactitud al entender que no se está ante un delito en el que haya de concurrir irremediablemente la variante de la intencionalidad ${ }^{82}$, y tampoco tiene sentido alguno que esto sea así. Las palabras de la autora abundan en transparencia, al disponer que en la mayoría de crímenes de ecocidio consumados por las corporaciones el daño medioambiental no es provocado de manera intencionada, considerándose como un mero derivado de aquellas decisiones enfocadas en maximizar los beneficios ${ }^{83}$. Conciencia tranquila en unas entidades que sobresalen por su absoluta falta de preocupación en las consecuencias que comporta abrazar una lógica productivista de previsible desenlace fatal.

De lo anterior se desprende la poca trascendencia que tiene para Higgins la concurrencia de elementos tan distintivos como pueden ser el conocimiento de que efectivamente se vaya a causar un daño y la intencionalidad o no del sujeto responsable, siendo relevante tan solo las consecuencias vinculadas a una actuación determinada a la hora de atribuir responsabilidad penal. El ánimo del sujeto o estar al corriente del posible resultado vendrían acompañados de una mayor pena, pero de ninguna forma condicionarían la certeza de estar hablando de un ecocidio ${ }^{84}$.

Hasta aquí lo compartido en relación con los aspectos definitorios que estipula Higgins. Aun sabiendo que el espíritu de esta obra es asimilar la enorme dificultad que conlleva conceptualizar un crimen de tales magnitudes, no puede pasar desapercibida, debido a la excelencia y vehemencia del mensaje, la revisión que hace esta autora con respecto a los endebles intentos desplegados

\footnotetext{
82 lbíd., p. 8.

83 lbíd., p. 23.

84 Ibíd., p. 174. Una vez llegado el momento de evaluar el grado de seriedad de un supuesto de ecocidio, Higgins propone una serie de preguntas que pueden allanar el camino para verificar la magnitud del caso en cuestión:

1) ¿Cuán previsible era el ecocidio?

2) ¿Cuán por debajo se encontraba la actitud del demandado en comparación con los estándares mínimos aplicables?

3) ¿Cuán común es en esta organización el tipo de infracción que condujo a la contaminación/daño medioambiental? ¿Qué extensión tuvo el incumplimiento? ¿Se trató de un caso aislado o más bien fue indicativo de una desviación sistemática de las buenas prácticas en las actividades del demandado?

4) ¿Hasta dónde llega la violación y el grado de culpabilidad dentro de la estructura de mando de la empresa?
} 
por detener la decadencia ecológica que la praxis habitual ha coadyuvado. Reprobando los fútiles arrebatos de conciencia ecológica de cualquier liderazgo político existente, respalda la inviabilidad de proseguir por el camino hasta ahora elegido. Severa en su discurso, Higgins desmonta enérgicamente la fantasía creada alrededor de las Naciones Unidas, al haberse desfigurado drásticamente el aparente rol de altavoz reproductor de las demandas procedentes de las personas más desfavorecidas. Esto ha conllevado a que las negociaciones climáticas se hayan convertido en un auténtico fracaso y, sobre todo, hayan avivado el descontento de la gente y la desconfianza en la clase política. Más aun, Higgins sentencia que la obligación que se tiene para con el pueblo desde las Naciones Unidas, ha sido desfigurada sin ningún escrúpulo y refocalizada hacia los intereses empresariales y las presiones políticas ${ }^{85}$.

Por otra parte, y al igual que hacía Broswimmer, también aborda la urgencia de reconstruir al coloso intocable: el modelo económico. Higgins denuncia que la representación de la naturaleza como mercancía, despedazándola e implantando el fenómeno de la propiedad privada allí donde sea posible, ha facultado a quien ejerce la titularidad sobre esa posesión a actuar sin ningún tipo de control ${ }^{86}$. Migrar hacia un nuevo modelo económico se ha convertido en vital para frenar la hecatombe ecológica que tantos avisos se están percibiendo.

Discurrir transversalmente y con tanto empeño por las contribuciones de Higgins puede explicarse como si se tratara de un reflejo espontáneo en respuesta a la habilidad que ha tenido para transmitir optimismo, contagiar su devoción y motivar a las personas para que sean partícipes en hacer realidad el visionario trabajo de esta abogada y activista. Su legado continuará influyendo de forma exponencial, siendo una cuestión de tiempo vivenciar el momento en que las leyes estén enteramente al servicio de prevenir y sancionar el ecocidio.

\section{El pragmatismo de Laurent Neyret como respuesta a la tesis maximalista de Higgins}

\footnotetext{
85 lbíd., p. 29-30.
}

86 lbíd., p. 42. 
Este largo viaje revelando las idas y venidas en la costosa labor de construir un concepto lo suficientemente sólido como para dar cobertura al repertorio de fundamentos teóricos que lo acompañan, quedaría incompleto si se omitieran las aportaciones de Laurent Neyret.

Paralelamente a la campaña de Higgins, desde 2012 a 2014 se gestó en Francia toda una investigación sobre el ecocidio y el auge de las "ecomafias", patrocinada por la agrupación de interés público Mission de Recherche: Droit \& Justice, la cual estuvo financiada principalmente por el Ministerio de Justicia y el Centro Nacional para la Investigación Científica de Francia ${ }^{87}$. Entre las personas que estuvieron al frente de la misma se encontraba Laurent Neyret y, a raíz de las indagaciones efectuadas, en 2015 se publicaban dos proyectos de convenciones internacionales cuyo impacto ha sido bastante significativo: una Convención contra el Ecocidio y otra contra la Delincuencia Ambiental, también llamada Convención sobre los "Ecocrímenes".

Antes de llevar a cabo un breve comentario sobre la idea que tiene Neyret del ecocidio, es importante esclarecer la distinción que concibe entre este y los "ecocrímenes". En este sentido, y atendiendo a lo previsto por Martin-Chenut, Neyret y Perruso, se puede decir que lo que en realidad encierra la diferenciación mencionada es realzar la importancia que tiene implantar una graduación entre los distintos tipos de crímenes. De acuerdo con Martin-Chenut et al., esta clasificación simplificaría la costosa labor de distinguir correctamente entre el respeto de la normativa administrativa y sus valores intrínsecos, por un lado, y el respeto de un valor superior ligado a la seguridad del planeta, por el otro, siendo la vulneración de este último lo que justificaría una respuesta penal ambiental88. Lo que se desprende de la investigación liderada sobre todo por Neyret y lo que viene a señalar en esta colaboración conjunta es que abogar por una clasificación internacional de los delitos ambientales, por medio de sendas convenciones, facilitaría la categorización entre infracciones administrativas, ecocrímenes y ecocidio, al agrupar en estos instrumentos internacionales

87 Más información sobre esta agrupación de interés público puede encontrarse en <http://www.gip-recherche-justice.fr/> [Última consulta, 17 de septiembre de 2019].

88 Kathia Martin-Chenut, Laurent Neyret y Camila Perruso, "Towards the internationalization of criminal protection of the environment: From ecocrimes to ecocide", Brazilian Journal of International Law, Vol. 12, oㅡ 2, 2015, p. 546 <http://dx.doi.org/10.5102/rdi.v12i2.3753> [Última consulta, 19 de septiembre de 2019]. 
aquellos comportamientos que deben llevar aparejada una consecuencia penal. Además, Martin-Chenut et al. sostienen que internacionalizar la protección ambiental desde el ámbito del derecho penal animaría la simplificación de los derechos nacionales, mediante la descriminalización de aquellos actos que no justificarían una consecuencia penal, favoreciendo así una mejor articulación entre las sanciones civiles, administrativas y penales ${ }^{89}$.

En suma, Martin-Chenut et al. convienen en que la pormenorización de actos englobados dentro del derecho penal ambiental, y volcada esta enumeración al plano internacional, permitiría la armonización de las legislaciones nacionales, reduciendo así el margen de discrecionalidad de los Estados en lo que respecta a la persecución de la criminalidad ambiental transnacional ${ }^{90}$. Por consiguiente, continúan diciendo que este modelo internacional del cual servirse dotaría de coherencia a la tipificación de los crímenes ambientales, enmarcando los delitos comunes, por un lado, y los delitos ambientales graves que merecen una solución excepcional específica (esto es, el ecocidio), por el otro, constituyendo así un sistema internacional penal congruente y armonizado ${ }^{91}$.

Tras esta breve aclaración, toca cumplir con lo prometido y pasar a la conceptualización que Neyret establece del mismo. A pesar de su extensión, la rigurosidad obliga a presentar el texto íntegro de la definición:

Article 2-Definition of Ecocide

1. For the purpose of this Convention, ecocide means the intentional acts committed in the context of a widespread and systematic action that have an adverse impact on the safety of the planet, such acts being defined as follows:

a) The discharge, emission or introduction of a quantity of substances or ionizing radiation into air or atmosphere, soil, water or the aquatic environments;

b) The collection, transport, recovery or disposal of waste, including the supervision of such operations and the after-care of disposal sites,

\footnotetext{
89 lbíd., p. 547.

90 Ibíd.

91 lbíd.
} 
and including action taken as a dealer or a broker in the framework of any activity related to the waste management;

c) The operation of a plant in which a dangerous activity is carried out or in which dangerous substances or preparations are stored or used;

d) The production, processing, handling, use, holding, storage, transport, import, export or disposal of nuclear materials or other hazardous radioactive substances;

e) The killing, destruction, possession or taking of specimens of wild fauna or flora species whether protected or not;

f) Other acts of a similar character committed intentionally that adversely affect the safety of the planet.

2. The acts referred to in paragraph 1 adversely affecting the safety of the planet when they cause:

a) A widespread, constant and serious degradation of the quality of air or the atmosphere, the quality of soil or the quality of water, the fauna and flora or their ecological functions; or

b) Death, permanent disabilities or other incurable serious illnesses to a population or they strip permanently the latter of their lands, territories or resources.

3. The acts referred to in paragraph 1 must have been committed intentionally and with the knowledge of the widespread and systematic nature of the actions in whose framework the aforementioned acts are being carried out. These acts shall also be deemed intentional where their perpetrator either knew or should have known that there existed a high probability that such acts may adversely affect the safety of the planet. ${ }^{92}$

\footnotetext{
92 Laurent Neyret, From Ecocrimes to Ecocide. Protecting the Environment Through Criminal Law, C-EENRG Reports 2017-2, Cambridge Centre for Environment, Energy and Natural Resource $\begin{array}{lllll}\text { Governance, University of } & \text { 37-38 }\end{array}$ <https://www.ceenrg.landecon.cam.ac.uk/report-files/report-002/view> [Última consulta, 21 de septiembre de 2019]. Cabe destacar que en el texto original no aparece separada la letra f) del apartado 1, sino que continúa en el apartado 1 letra e) tras el punto y aparte. Este punto y aparte, además de la naturaleza análoga de la frase, dan a entender que en realidad se trata de una errata y habría de aparecer como una letra separada, en concreto la f). En adición, en otro artículo de Neyret también se recoge el texto de este proyecto de Convención en portugués y sí que existe el apartado 1 letra f). Véase Martin-Chenut, Neyret y Perruso, "Towards the internationalization..." cit., p. 561. Traducción al castellano:

"Artículo 2 - Definición de Ecocidio
} 
Sería desacertado dar por concluido el presente apartado sin haber compartido previamente una opinión crítica sobre la definición recientemente expuesta. Dicho esto, si se toma la molestia de contrastar el artículo anterior con la idea de ecocidio reinante en la teoría de Higgins, son palpables las divergencias de percepción. A continuación se ha decidido recapitular lo que es de interés para resaltar las discordancias más llamativas.

Para empezar, es indiscutible que uno de los puntos cardinales del pensamiento de Higgins es la atribución de responsabilidad en base a las consecuencias, siendo también uno de los aspectos que más la alejan de lo planteado por Neyret. Como ya se ha dicho, en las contribuciones de Higgins no tiene cabida la exigencia de intencionalidad o negligencia en el sujeto al momento de cometer la acción, anteponiéndose las consecuencias derivadas de la misma para precisar la responsabilidad del autor de un hecho calificado como ecocidio. Por el contrario, para Neyret es condición sine qua non la existencia de intencionalidad en el sujeto $\mathrm{o}$, al menos, la concurrencia de conocimiento $\mathrm{o}$ negligencia grave, dado que cataloga también como ecocidio aquellos casos en

1. A los efectos de la presente Convención, se entiende por ecocidio aquellos actos intencionales definidos a continuación, cuando sean cometidos en el contexto de una acción generalizada y sistemática y tengan un impacto negativo en la seguridad del planeta:

a) El vertido, emisión o introducción de una cantidad de sustancias o de radiaciones ionizantes en el aire o la atmósfera, en el suelo, el agua o los medios acuáticos;

b) La retirada, el transporte, la recuperación o la eliminación de residuos, incluida la supervisión de dichas operaciones y el mantenimiento posterior de los vertederos, así como las medidas adoptadas como negociante o intermediario en cualquier actividad relacionada con la gestión de residuos;

c) La explotación de una instalación en la que se lleve a cabo una actividad peligrosa o en la que se almacenen o utilicen sustancias o preparados peligrosos;

d) La producción, el tratamiento, la manipulación, la utilización, la posesión, el almacenamiento, el transporte, la importación, la exportación o la eliminación de materiales nucleares $\mathrm{u}$ otras sustancias radiactivas peligrosas;

e) La muerte, destrucción, posesión o apropiación de especímenes de especies de fauna o flora salvajes, estén o no protegidas;

f) Otros actos de carácter análogo cometidos de forma intencionada y que afecten negativamente a la seguridad del planeta.

2. Los actos referidos en el apartado 1 afectan negativamente a la seguridad del planeta cuando causen:

a) Una degradación extensa, duradera y grave de la calidad del aire o de la atmósfera, de la calidad del suelo o de las aguas, de la fauna o la flora o de sus funciones ecológicas; 0

b) La muerte, invalidez permanente $u$ otras enfermedades graves e incurables a una población, o la expropiación permanente de sus tierras, territorios o recursos.

3. Los actos referidos en el apartado 1 deben ser cometidos intencionadamente y con conocimiento del carácter generalizado y sistemático de las acciones en cuyo marco se lleven a cabo dichos actos. Estos actos también se consideran intencionales cuando su autor supiera o debiera haber sabido que existía una alta probabilidad de que tales actos pudieran afectar negativamente a la seguridad del planeta." (Fuente: elaboración propia). 
los que el autor, habiendo cometido alguno de los actos recogidos en el artículo (o análogos), supiera o debiera haber sabido que existía una alta probabilidad de que esos actos pudieran acarrear un impacto negativo en la seguridad del planeta. Por otro lado, no hay rastro alguno en el pragmatismo de Neyret sobre la dicotomía que sugiere Higgins, quien apuesta por discernir entre un ecocidio debido a la acción humana y otro causado por eventos naturales, justificándose en última instancia en que la actual crisis climática antropogénica intensifica la aparición de estos eventos. Y para zanjar con aquellas características que distancian a Higgins y Neyret, mientras que este último estima la "seguridad del planeta" y su salvaguarda como el rasgo diferenciador, Higgins lo sitúa en el ecosistema y el disfrute pacífico del mismo por sus habitantes (independientemente de la especie).

Por medio de lo recién formulado se han podido dilucidar brevemente los principales roces entre ambas posturas. Añadir como elementos comparativos las teorías de Falk, Gray o Drumbl, entre otras, requeriría de una extensión que desafortunadamente no se dispone. No obstante, al haber ido recogiendo los componentes básicos de cada una de ellas, se ha procurado entregar toda una serie de herramientas para ir despejando progresivamente el camino hacia la culminación de una conceptualización lo suficientemente sólida.

\section{CONCLUSIÓN}

Klaus Bosselmann emplea una metáfora idónea para ilustrar lo que han significado las políticas ambientales de estos últimos tiempos, la cual vale la pena recuperar en este momento. Para Bosselmann, mientras que esta normativa se vanagloria de haber salvado unos cuantos "árboles", ha descuidado el "bosque" entero, echándolo a perder. En otras palabras, el lavado de conciencia de éxitos aislados lo único que provoca es disfrazar y prorrogar la toma de conciencia de una evidente realidad: el intento por mitigar el grave daño ecológico que originan las economías industriales modernas y el ritmo de vida actual, ha sido extremadamente deficiente ${ }^{93}$. Bosselmann no exagera lo más

\footnotetext{
${ }^{93}$ Klaus Bosselmann, "Losing the Forest for the Trees: Environmental Reductionism in the Law", Sustainability, Vol. 2, no 8,2010 , p. 2424-2425 <https://doi.org/10.3390/su2082424> [Última consulta, 23 de septiembre de 2019].
} 
mínimo cuando advierte de que la agencia humana ha condenado a la integridad de los sistemas ecológicos del planeta a un estado crítico difícil de revertir ${ }^{94}$.

La mitigación ambiental que promueven estas políticas es resultado de lo que Bosselmann llama reduccionismo ambiental, la idea delimitada, fragmentada y antropocéntrica de la naturaleza ${ }^{95}$. Estas políticas, si bien han constituido un avance en la protección del medio ambiente, no se encaminan a la deconstrucción de los valores primarios antropocéntricos de las sociedades actuales y poco hacen por romper con esa percepción reduccionista de una naturaleza fraccionada en mercancías al servicio del "progreso" de la humanidad. Frente a ello, y en un instante en el que los movimientos climáticos están acaparando cada vez mayor espacio de incidencia social y política, urge reformular los viejos prismas y dotar a las nuevas políticas de una fundamentación proveniente de la ética ambiental, teniendo como aspiración la justicia más allá de las propias construcciones sociales del ser humano.

$Y$ es aquí donde el crimen de ecocidio ha de entrar en escena: catalogar la destrucción de ecosistemas como uno de los crímenes internacionales más graves es estar a la altura de las circunstancias. Se ha vuelto imprescindible la existencia de una figura jurídica como el ecocidio para atajar la impunidad ambiental a través de consecuencias penales que respondan a la magnitud de los hechos. Tal y como se anticipaba al inicio de esta obra, mediante la divulgación de este concepto y la doctrina que ha ido madurando en torno a él, se ha tratado de convocar al activismo académico para que refuerce los fundamentos teóricos subyacentes a este crimen.

\section{BIBLIOGRAFÍA}

ACOSTA ESTÉVEZ, José B., Aspectos jurídicos de la crisis del Golfo Pérsico, Tesis Doctoral dirigida por Joan Lluís Piñol i Rull, Universitat de Girona, Departament de Dret Públic, 1993 <http://hdl.handle.net/10803/7685> [Última consulta, 12 de agosto de 2019].

\footnotetext{
94 Ibíd.

95 Ibíd., p. 2431-2433.
} 
BERAT, Lynn, "Defending the Right to a Healthy Environment: Toward a Crime of Geocide in International Law", Boston University International Law Journal, Vol. 11, ํo 2, 1993, p. 327-348.

BOSSELMANN, Klaus, "Losing the Forest for the Trees: Environmental Reductionism in the Law", Sustainability, Vol. 2, no 8, 2010, p. 2424-2448 $<$ https://doi.org/10.3390/su2082424> [Última consulta, 23 de septiembre de 2019].

BROSWIMMER, Franz J., Ecocide: A Short History of the Mass Extinction of Species, Pluto Press, Londres, 2002.

DRUMBL, Mark A., "Waging War Against the World: The Need to Move from War Crimes to Environmental Crimes", Fordham International Law Journal, Vol. 22, № 1, 1998, p. 122-153 <https://ir.lawnet.fordham.edu/lij/vol22/iss1/3/> [Última consulta, 9 de septiembre de 2019].

FALK, Richard A., "Environmental Warfare and Ecocide - Facts, Appraisal and Proposals", Revue Belge de Droit International, Vol. 1, 1973, p. 1-27 $<$ http://rbdi.bruylant.be/public/index.php?module_id=00000000009\&rec_id=000 00021562_00000011782> [Última consulta, 10 de septiembre de 2019].

GALSTON, Arthur W., "Science and Social Responsibility: A Case History", Annals of the New York Academy of Sciences, Vol. 196, Issue 4, 1972, p. 223235.

- "An Accidental Plant Biologist", Plant Physiology, Vol. 128, Issue 3, 2002, p. 787 <http://www.plantphysiol.org/content/plantphysiol/128/3/786.full.pdf> [Última consulta, 11 de agosto de 2019].

GAUGER, Anja, POUYE RABATEL-FERNEL, Mai, KULBICKI, Louise, SHORT, Damien y HIGGINS, Polly, The Ecocide Project: "Ecocide is the missing 5th Crime Against Peace", Human Rights Consortium, Londres, 2013 <https://sasspace.sas.ac.uk/4830/> [Última consulta, 12 de agosto de 2019].

GRAY, Mark Allan, "The International Crime of Ecocide", California Western International Law Journal, Vol. 26, № 2, 1996, p. 215-272. 
GUTIÉRREZ ESPADA, Cesáreo y CERVELL HORTAL, María José, El Derecho Internacional en la encrucijada. Curso General de Derecho Internacional Público, Editorial Trotta, Madrid, 2012 (3를 edición).

HIGGINS, Polly, Earth is our Business: changing the rules of the game, Shepheard-Walwyn (Publishers) Ltd., Londres, 2012.

- Eradicating Ecocide: Laws and governance to prevent the destruction of our planet, Shepheard-Walwyn (Publishers) Ltd., Londres, 2015 (2ª edición).

JOHNSTONE, L. Craig, "Ecocide and the Geneva Protocol", Foreign Affairs, Vol. 49, ำ 4, 1971, p. 711-720.

KUSTER, Etienne (coord.) y MELZER, Nils, Derecho Internacional Humanitario: Una Introducción Integral, Comité Internacional de la Cruz Roja, Ginebra, 2016 $<$ https://www.icrc.org/es/publication/derecho-internacional-humanitario-unaintroduccion-integral> [Última consulta, 18 de agosto de 2019].

LYTTON, Christopher H., "Environmental Human Rights: Emerging Trends in International Law and Ecocide", Environmental Claims Journal, Vol. 13, ํo 1, 2000, p. 73-91.

MALHOTRA, Saloni, "The International Crime That Could Have Been But Never Was: An English School Perspective on the Ecocide Law", Amsterdam Law Forum, Vol. $9, \quad n^{-} \quad 3, \quad 2017, \quad$ p. $\quad 49-70$ <http://amsterdamlawforum.org/article/view/408/553> [Última consulta, 11 de agosto de 2019].

MALJEAN-DUBOIS, Sandrine, "À propos de «Environmental Warfare and Ecocide. Facts, Appraisal and Proposals» de Richard Falk (1973-I): l'écocide et le droit international, de la guerre du Vietnam à la mise en péril des frontières planétaires", Revue Belge de Droit International, Vol. 48, oㅡ 1-2, 2015, p. 359367.

MARTIN-CHENUT, Kathia, NEYRET, Laurent y PERRUSO, Camila, "Towards the internationalization of criminal protection of the environment: From ecocrimes to ecocide", Brazilian Journal of International Law, Vol. 12, № 2, 2015, p. 540-569 <http://dx.doi.org/10.5102/rdi.v12i2.3753> [Última consulta, 19 de septiembre de 2019]. 
McCAFFREY, Stephen, "The Law of International Watercourses: Ecocide or Ecomanagement?", Revista Jurídica Universidad de Puerto Rico, Vol. 59, ํo 4, 1990, p. 1003-1012.

NEYRET, Laurent, From Ecocrimes to Ecocide. Protecting the Environment Through Criminal Law, C-EENRG Reports 2017-2, Cambridge Centre for Environment, Energy and Natural Resource Governance, University of Cambridge, 2017 <https://www.ceenrg.landecon.cam.ac.uk/report-files/report002/view> [Última consulta, 21 de septiembre de 2019].

PETTIGREW, Harry W., "A Constitutional Right of Freedom from Ecocide", Environmental Law, Vol. 2, ㄲo 1, 1971.

RODRÍGUEZ QUINTANA, César, La contaminación marina causada por el transporte de hidrocarburos en buques tanque: accidentes, legislación preventiva e indemnizaciones a las víctimas de mareas negras, Tesis Doctoral dirigida por Enrique Melón Rodríguez y Santiago Iglesias Baniela, Universidad de La Laguna, Departamento de Ingeniería Agraria, Náutica, Civil y Marítima, Área de Ciencias y Técnicas de la Navegación, 2008 $<$ https://www.educacion.gob.es/teseo/imprimirFicheroTesis.do?idFichero=tpcO 1DDDPE0\%3D> [Última consulta, 6 de septiembre de 2019].

SCHWABACH, Aaron, "Ecocide and Genocide in Iraq: International Law, the Marsh Arabs, and Environmental Damage in Non-International Conflicts", Colorado Journal of International Environmental Law \& Policy, Vol. 15, ํㅜ 1, 2004, p. $1-28<$ https://ssrn.com/abstract=442541> [Última consulta, 5 de septiembre de 2019].

SOLER FERNÁNDEZ, Rosel, "El ecocidio: ¿crimen internacional?”, bie3: Boletín $\begin{array}{llllll}\text { I.E.E.E, } & \text { ㅇ } & 8, & 2017, & \text { p. }\end{array}$ <http://www.ieee.es/Galerias/fichero/BoletinesIEEE3/2017/boletinieee8.pdf> [Última consulta, 10 de agosto de 2019].

TECLAFF, Ludwik A., "Beyond Restoration - The Case of Ecocide", Natural Resources Journal, Vol. 34, ㄲo 4, 1994, p. 933-956 <https://digitalrepository.unm.edu/nrj/vol34/iss4/6> [Última consulta, 6 de septiembre de 2019]. 
WESTING, Arthur H., Ecological Consequences of the Second Indochina War, SIPRI Publications, Taylor \& Francis, Londres, 1976.

- Weapons of Mass Destruction and the Environment, SIPRI Publications, Taylor \& Francis Londres, 1977.

- Warfare in a Fragile World: Military Impact on the Human Environment, SIPRI $\begin{array}{llll}\text { Publications, Taylor \& } \quad \text { Francis, Londres, } & 1980\end{array}$ <https://www.sipri.org/sites/default/files/files/books/SIPRI80Westing.pdf> [Última consulta, 3 de agosto de 2019].

ZIERLER, David, The Invention of Ecocide: Agent Orange, Vietnam, and the Scientists Who Changed the Way We Think about the Environment, University of Georgia Press, Athens, Georgia, 2011. 